\title{
IMPACTS ASSESSMENT \\ FOR THE \\ NATIONAL IGNITION FACILITY
}

Prepared For:

Lawrence Livermore National Laboratory

Prepared By:

Bay Area Economics

M.Cubed

December, 1996 


\section{DISCLAIMER}

This document was prepared as an account of work sponsored by an agency of the United States Government. Neither the United States Government nor the University of California nor any of their employees, makes any warranty, express or implied, or assumes any legal liability or responsibility for the accuracy, completeness, or usefulness of any information, apparatus, product, or process disclosed, or represents that its use would not infringe privately owned rights. Reference herein to any specific commercial product, process, or service by trade name, trademark, manufacturer, or otherwise, does not necessarily constitute or imply its endorsement, recommendation, or favoring by the United States Government or the University of California. The views and opinions of authors expressed herein do not necessarily state or reflect those of the United States Government or the University of California, and shall not be used for advertising or product endorsement purposes.

Work performed under the auspices of the U.S. Department of Energy by Lawrence Livermore National Laboratory under Contract W-7405-ENG-48. 
January 21, 1996

Dr. William Hogan

Senior NIF Scientist

Lawrence Livermore National Laboratory

7000 East Avenue L-490

Livermore, CA 94551

Re: Findings of the NIF Academic Advisory Panel

Dear Bill,

On behalf of UC Berkeley's Academic Advisory Panel convened by the Institute of Urban and Regional Development, we want to let you know that the panel supports the content and findings contained in Bay Area Economic's report, "Impacts Assessment for the National Ignition Facility." After two meetings of the panel, select members sitting in on the industrial panel discussions, and thorough review of the final document, we can confirm that BAE has addressed our concerns voiced through the review process.

The background of the group as a whole was broad and covered the key areas of urban economics and technology development. This was useful in helping BAE develop and effectively use their methodology to assess the impacts of constructing the National Ignition Facility at the Livermore Laboratory. In addition to providing the Laboratory with a sound evaluation of developing the NIF, the report provides a practical analysis of eight new technologies with potential commercial application and a comprehensive review of technology and the economy. 
We appreciate the opportunity to work with the Laboratory and Bay Area Economics on this exciting endeavor with national significance and regional economic implications. We look forward to working with the Laboratory on future collaborative projects involving technology and economy.

Sincerely,

fud E. laves

Director and Chair of the Panel

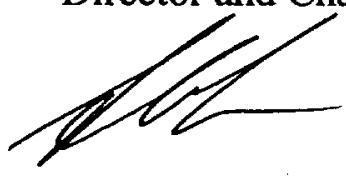

Steven Cohen

Professor

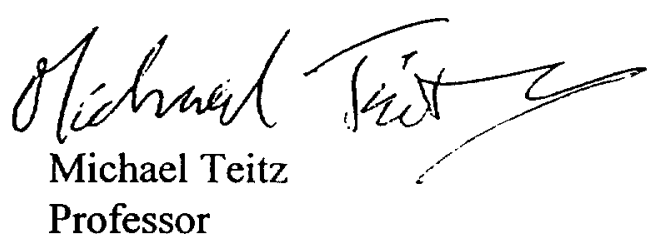

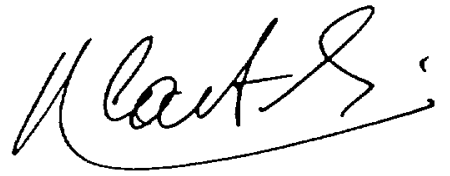

Manuel Cartels

Professor

Cynthia knoll

Cynthia Kroll

Regional Economist 


\section{ACKNOWLEDGEMENTS}

\section{Industry Experts}

\section{Bill Arnold}

Advanced Lithography

Advanced Micro Devices, Inc.

\section{Jim Glaze}

Vice President, Technology Programs

Semiconductor Industry Association

\section{John Grimes}

Vice President, Product Development

Titan Technologies, Inc.

\section{David Kelley}

Radar Program Manager

Amerigon, Inc.

\section{U.C. Berkeley Advisory Panel}

Manuel Castells

Professor

City and Regional Planning

\section{Steven Cohen}

Professor

City and Regional Planning

Judith Innes

Director/ Professor

Institute of Urban and

Regional Economics

\section{Cynthia Kroll}

Fisher Center for Real Estate

and Urban Economics

Michael Teitz

Professor

City and Regional Planning

Lawrence Livermore

National Laboratory

\section{Jeff Atherton}

Associate Project Leader

Laser Material and Optical Technology

\section{Gloria Conlin}

Technology Licensing

Pat Fitch

Director

Center for Healthcare Technologies

\section{David Markle}

Vice President, Advanced Technologies

Ultratech Stepper, Inc.

\section{Jack Salvador}

Advanced Lithography

Intel Corp.

\section{John Stauss}

President

Zircon, Corp.
Bill Grant

Technology Licensing

Andrew Hawryluk

Advanced X-Ray Optics

Bill Hogan

Senior NIF Scientist

Ralph Jacobs

Director

New Technology Initiatives

Dennis Matthews

Associate Program Leader

Technology Development

Tom McEwan

Electronics Engineer

\section{Mike Perry}

Associate Program Leader

Short Pulse Laser Applications and Technology

\section{Don Sweeney}

Deputy Program Leader

Advanced Microtechnology

\section{Steve Vernon}

Group Leader

Thin Film Technology

Steve Wampler

Public Affairs Office

\section{Consultants/U.C. Staff}

Dena Belzer

Principal

Bay Area Economics

Janet Smith-Heimer

Principal

Bay Area Economics

Raymond Kennedy

Senior Associate

Bay Area Economics

\section{Steve Moss}

M.Cubed

\section{Larry Barone}

Berkeley Roundtable on the International Economy

\section{Josh Kirschenbaum} Institute of Urban and Regional Economics

\section{Rick Freeman}

National Program Manager EUV Lithography 


\section{EXECUTIVE SUMMARY}

\section{Report Purpose}

This report documents the economic and other impacts that will be created by the National Ignition Facility's (NIF) construction and ongoing operation, as well as the impacts created by new technologies that may be developed as a result of NIF development and operation. Impacts stemming directly from the project's construction and operation can be expressed in terms of the number of jobs created, the quality of these jobs, and the implications these jobs have for the U.S. economy as a whole. However, the impacts related to the development of new technologies are less tangible and must be defined in more qualitative terms. This report does not address the basic rationale for building the NIF; however, documents that do provide this information are listed in Appendix A.

\section{Methodology}

The employment estimates presented in this report principally rely on analyses developed by the Argonne National Laboratory, as contained in Technical Documentation in Support of the Draft-Specific Analysis for Construction and Operation of the National Ignition Facility, as well as other documents. The Argonne estimates are based on the Regional Input-Output Modeling System (RIMS) and present direct, indirect and induced employment estimates.

Impacts generated by technology "spin-offs" or transfers related to the NIF itself cannot be documented at this time, since the NIF itself has not been built. However, using a general literature review on the impacts of technological innovation on economic growth, the history of technology transfers generated by the DOE National Laboratory system, and case studies of eight technological innovations already generated by the ICF program at LLNL during previous similar projects, it was possible to determine the general manner in which these impacts are likely to occur; and to qualitatively asses the basic characteristics and potential significance of these impacts.

\section{Four Key Impact Areas}

The literature on the role of technology in economic growth, a review of the National Lab's general experience with technology transfer, and discussions with academic researchers, LLNL personnel, and industry experts, indicate that there are four areas where new technologies associated with the NIF are likely to have an impact. These four include:

- Impacts on the economy

- Impacts on science and technology

- Impacts on quality of life

- Impacts on the Lab 


\section{Conclusions}

Technological innovations linked to the existing ICF program at LLNL will have a significant impact on the U. S. economy. This trend should continue with the NIF which is already pushing the state of the art in several key technology areas. These innovations could have only been made at LLNL because of the unique research environment which includes extensive use of basic science, time frames for resolving research issues that are much longer than is typical in private industry, the large interdisciplinary teams of scientists, and the tremendous laboratory infrastructure. Although these innovations are not central to the Lab's core mission, the United States will only be able to maximize the return on its investment in the National Labs by allowing industry to benefit from these spin-off technologies. The impacts of these innovations extend beyond basic growth in the economy to include benefits for science and technology, overall quality of life, and positive residual benefits that flow back into the National Laboratory system. The following statements, organized by the major impact categories, summarize the significant findings of this report.

\section{Economic Impacts}

1. Past discoveries from the ICF program at LLNL have the potential to impact industries which account for a significant portion of the current U.S. gross domestic product (GDP). The specific examples studied (EUV Lithography and MIR) may have important impacts on industries representing $\$ 600$ billion, or 10 percent of the U.S. GDP.

2. NIF and the expanded ICF program will push the state of the art in several technology areas that are likely to have significant impacts on the economy over the next 10 to 15 years.

3. The total number of jobs created by the NIF's development, construction, and operation will peak at over 6,000 nationally, with over 3,000 in the San Francisco Bay Area. While this is a relatively small fraction of the total employment in the area, the quality of these jobs will be very high and will help the U.S. retain its competitiveness in several key sectors.

4. The NIF's full potential to generate economics benefits can only be realized if the National Labs continue to have strong interactive relationships with private industry.

5. LLNL must maintain both vigilance and flexibility to ensure that future innovations reach their full potential for dissemination into the economy. 


\section{Science and Technology Impacts}

6. Basic scientific research applicable to large, interdisciplinary projects, is the most powerful component driving technological innovation at LLNL.

7. Technological innovations emerging from the NIF are likely to be unique from innovations developed by other public or private research institutions in the U.S.

\section{Quality of Life Impacts}

8. Over the long run, the "quality of life" impacts from technological innovations made at LLNL may exceed the economic impacts and positively affect the lives of millions of people.

\section{Impacts on LLNL}

9. The Lab's missions and infrastructure will benefit from innovations in its spin-off projects.

10. By developing a close working relationship with industry, the Lab strengthens its own research capabilities. 
TABLE OF CONTENTS

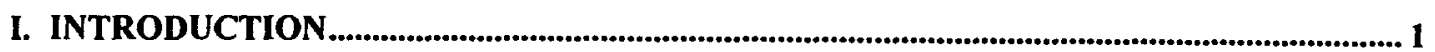

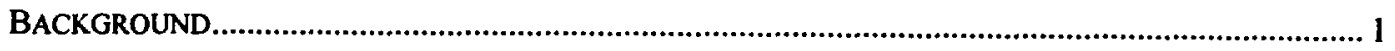

REPORT PURPOSE

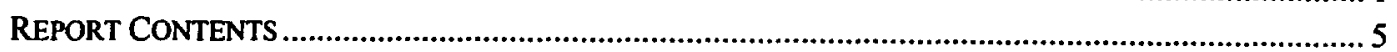

II. THE NATIONAL IGNITION FACILITY: AN OVERVIEW ................................................ 7

BACKGROUND

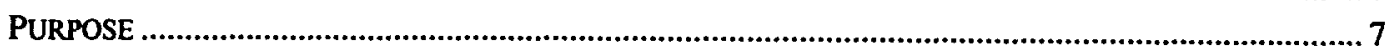

III. IMPACTS CREATED BY THE NIF'S DEVELOPMENT, CONSTRUCTION, AND

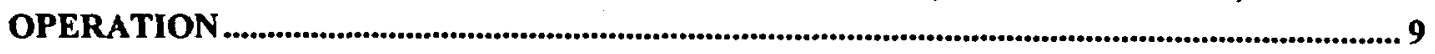

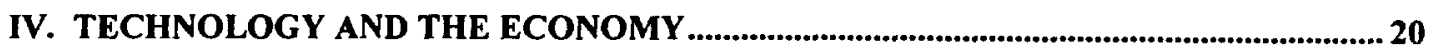

TECHNOMICS: THE ROLE OF TECHNOLOGY IN ECONOMIC GROWTH .............................................2 20

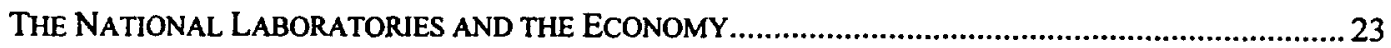

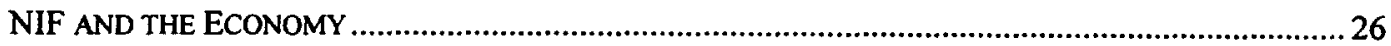

V. LASER RELATED TECHNOLOGY CASE STUDIES....................................................... 29

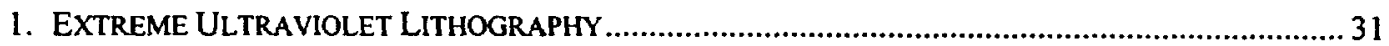

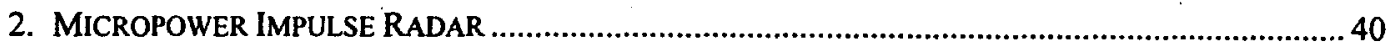

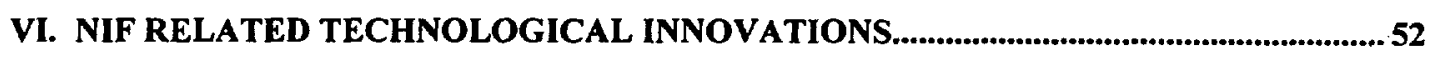

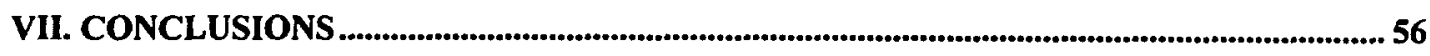

APPENDIX A: ADDITIONAL TECHNOLOGY PROFILES.....................................................6

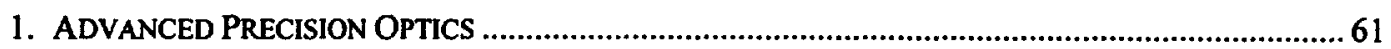

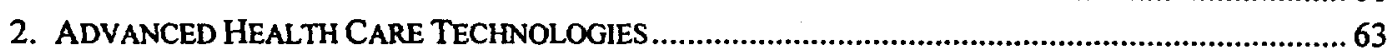

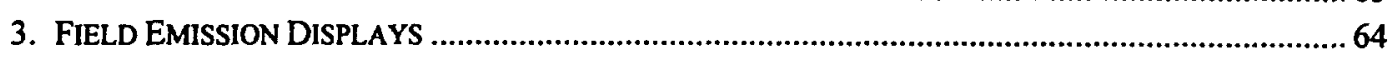

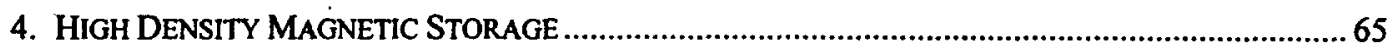

5. MICRO OPTICS

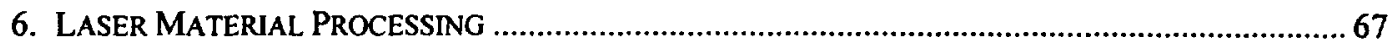

APPENDIX B: EUV AND MIR INDUSTRY PANEL DISCUSSION QUESTIONS ................ 68

APPENDIX C: DOCUMENTS JUSTIFYING NIF MISSION ................................................... 73

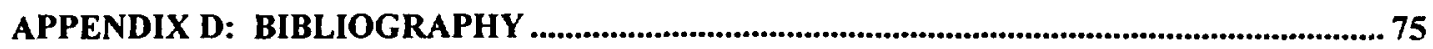




\section{INTRODUCTION}

\section{Background}

The U.S. Congress is currently in the third phase of a multi-step decision-making process regarding funding for the National Ignition Facility (NIF). The NIF, which is expected to be located at Lawrence Livermore National Laboratory (LLNL) in Livermore, California, will be a national research facility for the study of inertial confinement fusion (ICF) and high-energy-density science. This facility will build on the National Laboratory system's 25 years of experience with inertial fusion with applications relevant to national defense and energy research.

The first critical decision regarding the NIF, made in January 1993, was initial approval of mission need. This decision was the culmination of over four years of review by both the Department of Energy (DOE), the National Academy of Sciences, and other independent groups of experts who concluded that a National Ignition Facility would significantly enhance the national ICF program agenda. The 1993 decision resulted in funds being allocated in 1993 and 1994 for a conceptual design study, the report of which was issued in April 1994. In October 1994 the DOE made the second critical decision regarding the NIF by seeking funds to begin the engineering design, an environmental impact statement, a safety analysis, and to implement project management and control systems. The next critical decision during 1997 will be whether to allocate the funds necessary to procure and construct the NIF, followed several years later by a decision regarding approval to start testing and to begin operations.

The NIF's primary objective will be to provide scientific data to assist in the Department of Energy's ongoing Stockpile Stewardship and Management (SSM) program. This program, which is the method by which the U.S. government will maintain the safety and reliability of the country's nuclear arsenal through laboratory research and computer modeling, provides a viable alternative to nuclear weapons testing. There is extensive documentation of the need for this basic mission, and the role the NIF will play to provide the necessary scientific data for the SSM program (see Appendix C for a list of these documents). In addition, the NIF's environmental impacts have been studied in the Programmatic Environmental Impact Statement (PEIS) for the entire SSM program. However, there has been relatively little focus on the economic or other types of impacts that the NIF could generate for the U.S, other than the very basic socio-economic impacts considered in the PEIS.

\section{Report Purpose}

This report documents the impacts that will be created by the NIF's actual construction and ongoing operation, as well as the impacts created by new technologies that may be developed as a result of NIF development and operation. Impacts stemming directly from the project's construction and operation can be expressed in terms of the number of jobs 
created, the quality of these jobs, and the implications these jobs have for the U.S. economy as a whole. However, the impacts related to the development of new technologies are less tangible and must be defined in more qualitative terms.

\section{Report Research Methodology}

Economic impacts are typically measured by a number of different factors, including the quantity of jobs created or retained; the type of employment (e.g., manufacturing; construction) engendered; associated wages and salaries; changes in firm revenues, numbers and size; contributions to industrial "competitiveness;" productivity changes; and improvements in the quality of life. The extent to which these factors can be quantified depends on data availability and the reliability of statistical methods that measure the relationship between cause (e.g., investment) and effect (e.g., outcomes in terms of employment and other factors). For example, it is relatively well-known how a million dollar investment in a steel mill will affect steel production, employment and wages. On the other hand, while a million dollar investment in the biotechnology research sector may result in an increase in employment that can be calculated, it is less well understood how the investment will change production of bioproducts or alter our quality of life.

This study considers the impacts associated with two distinct types of activities. First, economic impacts associated with direct federal investment in NIF construction and operations. These impacts stem from the roughly one billion dollars required for successful NIF development and performance. The effect of the NIF's direct dollar investment on employment and personal income can be modeled with some accuracy based on standard economic methods, as described in Chapter III. In this case there is significant historical data indicating how a given level of investment is likely to relate to various forms of economic activity. In addition, the consequences of direct expenditures on other economic factors -- such as firm characteristics, competitiveness, and productivity -- are assumed to be minimal, as the investment itself is not expected to alter fundamental economic relationships. That is, one NIF dollar will purchase roughly the same amount of construction activity as any other high technology construction project. However, because of the NIF's high-technology characteristics -- and the fact that the San Francisco Bay Area has particular economic patterns -- these variables will be somewhat differently affected than other types of spending (e.g., on services), an element which is also discussed in Chapter III.

Second, economic and other types of impacts associated with technology "spin-offs" and "transfers" created by the types of products demanded by NIF development and operation. The NIF will require sophisticated optical, surveillance and other equipment which may act to push the state of the art in these and other technology areas. That is, NIF procurement and operations in themselves may create the need to develop new production methods and technologies that can be applied to other economic sectors. For example, advanced optical 
Figure 1

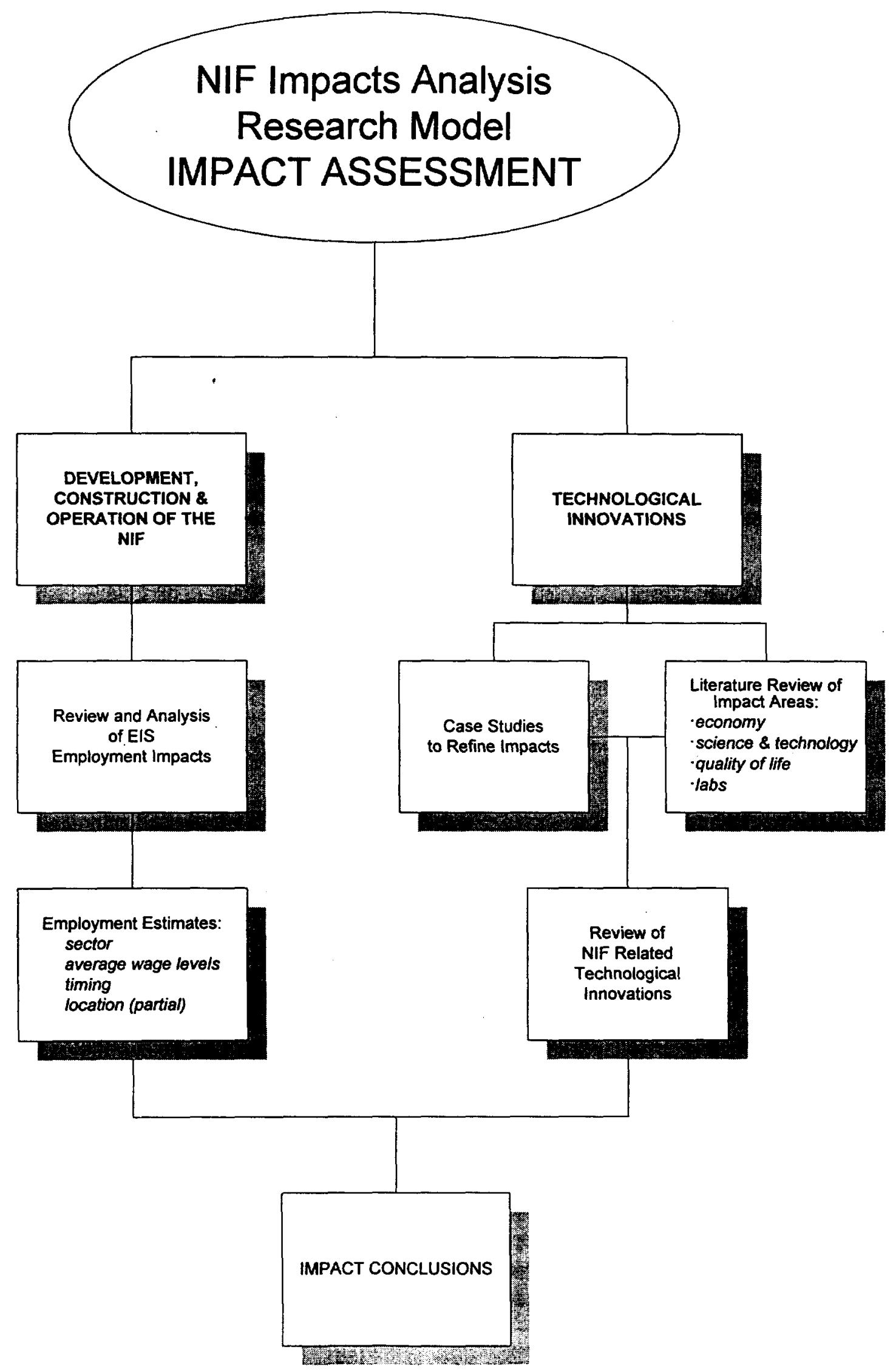


equipment developed specifically for the NIF may also have applications for televisions or other consumer devices. This category of impacts can dwarf the first category in terms of size and quality of benefits. However, by their very nature spin-off effects, while generally expected in high technology investments, cannot be predicted with great accuracy.

As discussed in the "Technology and the Economy" section of this report, economists and others have long struggled to develop methods to forecast technological innovation patterns, with limited success. This is because technology-based impacts are generated through a number of factors which sometimes are a repeat of past patterns, and other times represent entirely new paradigms. Likewise, technological innovation proceeds through a series of steps, each of which contains significant uncertainty of outcome. For example, a new product or process must be identified, developed into something which is scientifically, economically, and technologically feasible, introduced into the market, and successfully penetrate into its target sector. On each step new challenges and opportunities may arise-eight-track tapes are defeated by another sound delivery standard; or lasers are initially determined to be a poor weapon system, but excellent for medical and telecommunications applications.

While it is difficult to predict with accuracy the outcomes associated with technological innovation, it is possible to frame the potential magnitude of these impacts. This is particularly true in the case of the NIF, which builds upon past like projects developed at LLNL. That is, there is some historical data available with which to develop a judgment of likely NIF technology methodology to estimate potential technology-based impacts, as follows:

1) A literature review was conducted which focused on the general types of economic impacts that arise from technological innovation. This review also evaluated the DOE's National Laboratories past experience with technology transfer and resulting economic consequences. Through this information general insight and assumptions were formed about the characteristics and categories of impacts that may be expected from the NIF.

2) More importantly, LLNL's past experience with a similar, though smaller scale, laser program was investigated. That is, historical, mostly qualitative data, was used to predict possible future outcomes. This method follows the same type of cause and effect methodology employed to estimate investment impacts, albeit with less empirical data on which to base findings. This type of case study analysis is commonly used to inform a variety of actions, including business, scientific, and economic inquiries.

Eight technologies which have evolved from LLNL's existing laser program were selected for case study analysis. These particular technologies were examined because of their potential for commercial success, and are used to illustrate the potential for any one technology to result in significant economic benefits. Two of the study technologies were analyzed extensively because they are the most developed, and offer 
a clear set of commercial opportunities. The remaining six technologies are in less advanced stages, and are discussed more generally, with less detailed information about related industries and applications.

The eight case studies were completed through an iterative process. First, the project team consulted with a panel of academic advisors from the University of California, Berkeley. As a result of these discussions, and as supplemented by the literature review, the general types of impacts most likely to result from laser-related technological innovation were identified. Second, the project team developed a detailed description of the subject technologies including their characteristics, how they emerged from the laser program, potentially competing processes or products, and the economic sectors and industries they are likely to influence. As part of this analysis, the size and trends of the technologies which were studied in greater detail, panels of industry experts were provided a written list of questions prior to the interview, and these questions served as a framework for the ensuing discussion. And fourth, based on the information collected in the previous three steps, a further examination of potential technological innovations and related benefits was conducted based on available data.

The case studies provide a narrative description of possible impacts resulting from each technology. Although not completely empirical in nature, the case studies offer decision makers and others a better glimpse into the full range of potential economic benefits which may be derived from the NIF.

\section{Report Contents}

The following sections of this report cover five major topic areas:

The National Ignition Facility: An Overview. This section briefly describes the NIF and outlines its two mission objectives and two collateral benefits. The two primary missions include science based nuclear weapons stockpile stewardship and potential development of a new energy source. Primary collateral benefits include basic scientific research and long-term benefits to the economy.

Impacts Generated by the NIF's Development, Construction, and Operation. The NIF will generate employment in the construction phase and during ongoing operation. In addition, the procurement of specialized goods and materials may stimulate employment increases at supplier companies. This activity will both create wealth in terms of wages and salaries, and will expand the capabilities of firms who will be providing specialized goods and services to the NIF.

Technology and the Economy. To better understand the NIF's ultimate impact on the U.S. economy, this section examines how technological innovation contributes to economic growth, how the DOE National Labs have contributed 
technological advances in the economy, and what potential areas the NIF is likely to impact based on the more general experiences with other forms of technology innovation.

Laser Program Technology Case Studies. This section will examine the impacts resulting from new technologies developed in conjunction with the Lab's ongoing laser research program. Because it is impossible to accurately predict what the new technological innovations resulting from NIF may be, this section examines a sample of two new technologies that have come out of past research efforts associated with the inertial confinement fusion efforts in the laser program. The analysis of these technologies will provide insight into the types of impacts that could result from NIF related research.

NIF Technology Impact Areas. This discussion will indicate the areas in which the NIF is expected to push the existing technological envelope, and what indicates the potential commercial applications for these innovations.

Conclusions. The report's conclusions regarding the likely impacts of the NIF on the U.S. economy are based on the material presented concerning the impacts of technology on the economy, as well as on the case studies of the eight laser-related technologies. 


\section{THE NATIONAL IGNITION FACILITY: AN OVERVIEW}

\section{Background}

The construction of the National Ignition Facility (NIF) at Lawrence Livermore National Laboratory (LLNL) will represent the culmination 25 years of research in inertial confinement fusion (ICF) and advanced laser systems. Beginning in 1970, with its first neodymium glass laser, LLNL has built a series of lasers, each five to 10 times more powerful than its predecessor. The two-beam Janus laser, completed in 1974, demonstrated laser compression and thermonuclear burn of fusion fuel for the first time. Janus was followed by the Cyclops laser which was used to perform target experiments and to test optical designs for the future Shiva laser. Argus, the next laser to be brought on line, helped Lab scientists to understand laser-target interactions. In 1977 the Lab completed work on the 20-beam Shiva laser. While these advancements were taking place at LLNL, other laser programs in the U.S. and abroad were also underway. Major laser research facilities in the Soviet Union, Japan, China, Germany, France, and the United Kingdom were established or expanded.

Novette, completed in 1983, was the first laser designed to generate green and ultraviolet light. The Nova laser, which followed in 1985, has helped Lab scientists make important progress in understanding ICF. The NIF, which will be the world's most powerful laser, will build on these gains by demonstrating thermonuclear ignition and burn in the laboratory for the first time. Consisting of 192 laser beams whose energy can be focused onto a target capsule containing fusion fuel, the NIF will generate a fusion reaction that will produce more energy than was delivered by the laser beams, thus yielding net fusion energy gain. Furthermore, NIF experiments will produce conditions of high energy and density similar to those found at the center of the sun.

The NIF's 192 laser beamlines will require more than 8,000 large optic devices, as well as several tens of thousands of smaller optics. The size of the NIF building will approach that of a covered football stadium. The NIF will be designed, built, and operated by four participating organizations: Lawrence Livermore National Laboratory (LLNL) as the lead; Los Alamos National Laboratory; Sandia National Laboratory; and the University of Rochester.

\section{Purpose}

It is important to emphasize that the NIF laser is an experimental laboratory facility, not a weapons program, nor a device to be used for new weapons development. Rather, the NIF project has two mission objectives and two collateral benefits. 


\section{Mission Objectives:}

1. National Security. The NIF will be a cornerstone in the U.S. sciencebased stockpile stewardship program because it will be the only facility able to undertake experiments in the fusion and high-energydensity physics processes that occur in a nuclear weapon explosion. Science-based stockpile stewardship is the approach chosen by the DOE and Congress to ensure the safety, reliability, and security of the United States' existing nuclear weapons, without nuclear testing. The NIF will provide data essential to the evaluation of important nuclear weapons issues, including valuable information about changes in materials during implosion, and data necessary to asses the impact of cracks and other abnormalities on weapon performance. It is important to reiterate that the NIF will not enable LLNL or any of the other weapons laboratories to develop new weapons per se, but it will allow Lab scientists to evaluate issues for existing weapons, and improve test computational models for those designs.

2. Energy Resources. The NIF will give researchers the tools to determine whether inertial confinement fusion can be developed into a clean source of energy. Fusion power could become an important component of the world's energy inventory, reducing dependence on other environmentally damaging energy sources. Furthermore, if net fusion energy gain is demonstrated, as anticipated, the NIF will constitute a crucial step toward the goal of providing energy security for the U.S. in the $21^{\text {st }}$ century.

\section{Collateral Benefits:}

1. Science and Technology. For many areas of basic science including astrophysics, plasma physics, hydrodynamics, nuclear physics, materials science, non-linear optics, and computational physics, the NIF's ability to create conditions of high temperature and density will make possible previously unattainable laboratory research.

2. Industrial Competitiveness. U.S. industry will benefit from new technological advances as NIF's engineering and optics requirements are met. Such advances may be developed in collaboration with private sector firms, or transferred to them through Cooperative Research and Development Agreements (CRADAs), licenses, and other agreements. High technology jobs will be created to design, develop, and maintain the facility's components. Approximately 75 percent of NIF's $\$ 1.1$ billion budget will pass directly to industry,injecting funds into the economy in a range of technical categories. 


\section{IMPACTS CREATED BY THE NIF'S DEVELOPMENT, CONSTRUCTION, AND OPERATION}

Between fiscal years (FY) 1996 and FY 2002 over $\$ 1.0$ billion will be invested in NIF's construction and start-up operations. As indicated in Figure 2, more than half of these funds will be used to purchase sophisticated parts and equipment from manufacturing industries (e.g., optical and communication equipment). This equipment will be used to develop and implement the NIF laser, the experiment area, and recording, control, and diagnostic systems, some of which will form the basis for future spin-off technologies. Another $\$ 60.7$ million in FY96 dollars will be expended annually to operate the facility after construction is completed in FY 2002.

The NIF will also induce economic benefits related to leveraging other resources: new cooperative research and development (R\&D) efforts will be engendered by the project and as a result of technology transfer. For example, NIF's development will necessitate creation of new technology which may ultimately provide significant benefits to the multibillion dollar semiconductor industry. Likewise, NIF-driven research will potentially contribute to advances in radar, optics, and health care technologies. Procurement of NIF inputs, particularly optical components, will also encourage technological innovation. For example, the laser's demand for highly precise optical parts could lead to breakthroughs in optical design and development practices that may ultimately have commercial applications. These spin-off effects are discussed in detail in Chapters IV and V.

Construction and operating expenditures will create jobs at LLNL, in the surrounding communities, and in regions of the country from which NIF inputs (e.g., optical components, electrical circuits; precision parts) are purchased. The purpose of this discussion is to examine the level, characteristics, and geographic distribution of the employment gains induced by NIF investment. That is, the employment estimates contained in this Chapter are associated solely with direct expenditures on NIF construction and operation.

\section{Analytic Methodology}

The employment estimates presented in this Chapter principally rely on analyses developed by the Argonne National Laboratory, as contained in Technical Documentation in Support of the Draft-Specific Analysis for Construction and Operation of the National Ignition Facility, as well as other documents. The Argonne estimates are based on use of the Regional Input-Output Modeling System (RIMS). RIMS is an input-output (I/O) economic impact model developed by the U.S. Department of Commerce's Bureau of Economic Analysis (BEA). 


\section{Figure 2 Distribution of \$ Billion Investment in NIF Construction}

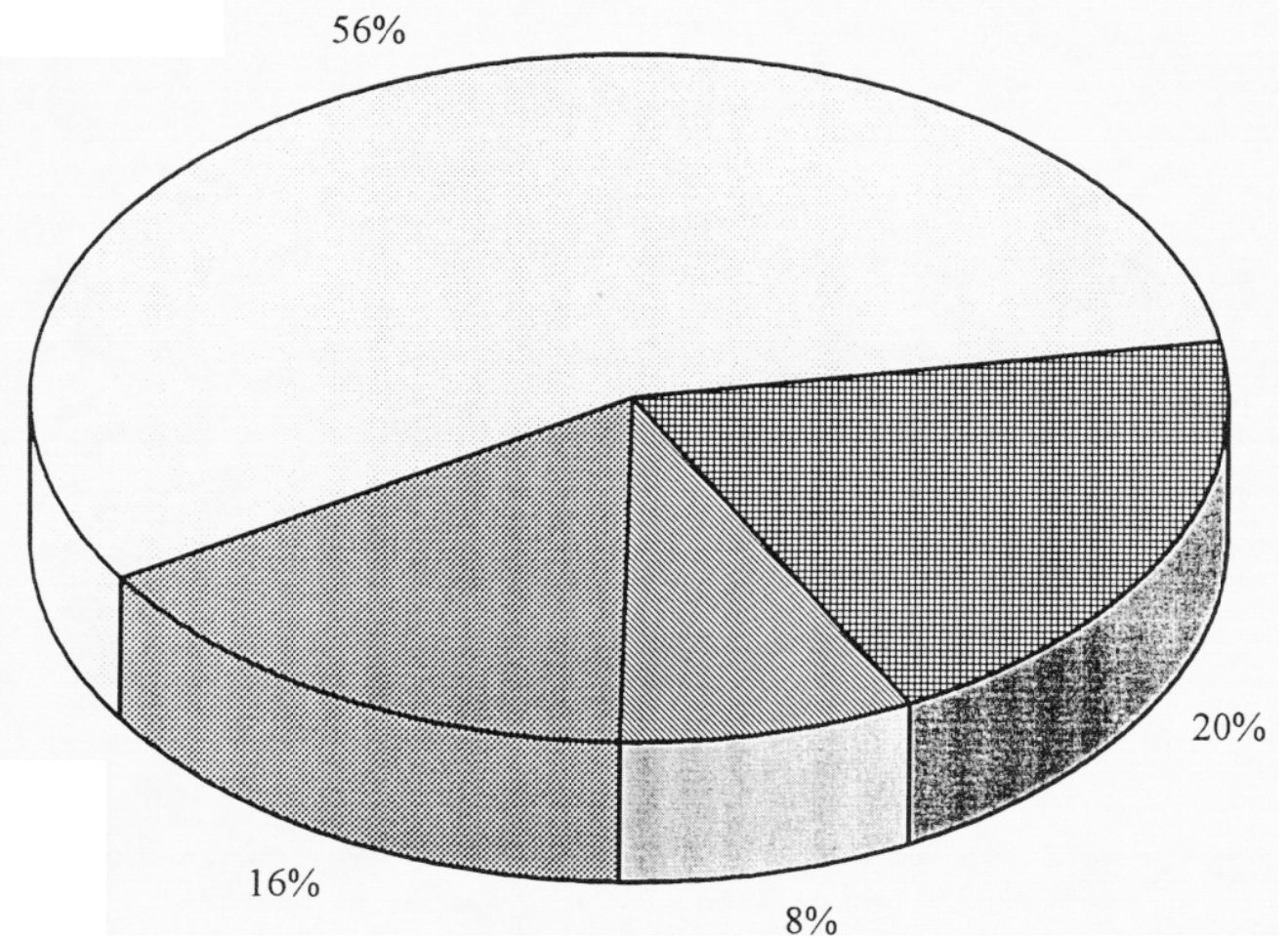

毘 Lawrence Livermore National Laboratories

Other Laboratories

[0 tru Industries

$\square \quad$ tur1

Source: LLNL 
I/O models use area-specific data on industrial and commercial activity to trace how a dollar of investment moves through a regional economy. RIMS is based on a table of direct requirement coefficients which indicates the inputs of goods and services required to produce a dollar's worth of output. Standard production functions-the capital, labor, and technology-needed to produce a given set of goods determine how changes in demand for goods and services ultimately affect the demand for the inputs to these services. For example, producing a ton of steel may require three workers and a particular set of equipment, which would not be required if the steel were no longer needed.

RIMS contains more than five hundred economic sectors, and uses economic census data to compile county-level wage and salary information at the four-digit standard industrial code (SIC) level. National data is adjusted for the subject region's-in this case the San Francisco Bay Area-industrial and trading patterns. Based on this structure, RIMS estimates the regional economic impact that would result from a dollar change in the output of local industries delivered to final demand (i.e., to ultimate purchasers, such as consumers outside the region).

RIMS is commonly used to evaluate economic activity in which changes in the total demand for output of the industries being studied results in changes in inputs and outputs by the local economic sectors. For example. RIMS has been used to estimate the impacts of such projects as construction and operation of new factories, development of tourism facilities, and military base closures.

Argonne estimated two levels of impacts, as follows:

- Direct on-site impacts. These were calculated based on direct data contained in the NIF Conceptual Design Report (CDR). That is, direct impacts reflect LLNL's estimates of the number of scientists, technicians, construction workers, and other on-site employees who will be needed to develop, construct, and operate the NIF. Direct impacts also include Lab estimates of the number of workers at other National Laboratories or research institutes who will be engaged in supporting NIF construction or operation.

- Indirect off-site impacts. These were estimated based on RIMS. Indirect impacts relate to employment created by NIF procurement. For instance, purchase of the necessary metal parts or glassware. Indirect impacts also include the resources expended by the individuals or firms which are directly affected by the investment. For example, building supply purchases-for wood and other material - may necessitate the hiring of additional workers at the lumber mill.

Argonne's analysis also included induced impacts. These are employment changes caused by the greater general spending created by the direct and indirect impacts. However, these estimates were reported by Argonne as part of the indirect effects (i.e., they were not reported as a separate line item). It should be noted that Argonne's definition of direct and 
indirect effects is different than that used for other $\mathrm{I} / \mathrm{O}$ models. This difference should be taken into account by analysts examining the NIF calculations. However, while the distribution of impacts between direct, indirect, and induced may differ from model to model, the aggregate impact effect should be similar.

Taken together, direct, indirect, and induced employment are termed the project's multiplier effect. The multiplier effect estimates how many times a given dollar of investment will be spent as it works its way through the economy. Multipliers can be applied to various categories. For example, income multipliers-additional spending associated with every dollar of income-tend to be less than one. This is because not all income is spent; some is saved, or used to pay-down debt. Employment multipliers-the number of jobs created per one million dollars of investment-can range from five to 65 depending in the type of job. Alternatively, employment multipliers can relate to the number of indirect and induced jobs engendered by a dollar of investment in direct employment. This multiplier category can be relatively low-less than two-to quite high.

Multipliers are low where simple products are being purchased. For example, buying a sandwich induces the need for unsophisticated labor-the sandwich maker-and basic inputs-agricultural products and bakeries. Investing in a space ship, on the other hand, may require the development of extremely sophisticated machinery and production processes, prompting a greater amount of secondary spending to develop the necessary high-value inputs. In addition, in state-of-the-art purchases such as high-technology manufacturing, the investment may induce an entirely new production paradigm, such as the creation of new manufacturing techniques or equipment. In these cases the multiplier may be quite high, as the investment results in even more productive and higher value output than existed prior to the funds being expended.

\section{Employment Estimates: NIF Construction Phase Impacts}

Regional and National Investment Effects. NIF construction will support jobs both in the San Francisco Bay Area and nationally. The precise locations where jobs will be created (i.e., where NIF funds will be invested) depends on where key inputs are purchased. It is expected that NIF expenditures will center on the San Francisco Bay Area because that is where the facility is likely to be located, and because the region has a significant concentration of high-technology firms capable of supplying the project.

Because NIF purchases will be competitively bid, it is not currently known precisely which firms from what locations will serve as project suppliers. A previous laser program developed at the Lab-Nova-purchased inputs from firms located in 44 states. In addition to California, significant expenditures for this program were made in New York, Pennsylvania, Connecticut, Ohio, and Michigan. The geographic distribution of U.S. optics and electronics firms has changed since the Nova program, and since NIF expenditures will be substantially larger it will almost certainly draw in more competitors than the Nova program. For example, the NIF's need for a large quantity of precision parts may encourage more supplier competition from such states as Washington, where a 
number of firms specializing in precision components are located.

As a first cut, however, Lab officials expect that the greatest portion of investment will be made in regions close to the LLNL. Less than half of the manufactured goods to be used by the NIF are assumed to be imported to Livermore from other parts of the country. As indicated in Table 1, it is assumed that most direct investment will take place in the San Francisco Bay Area, where almost all of the construction and operation-related labor expenditures will be made, and where most of the necessary facility materials will be purchased. Although within the region a significant portion of investment will occur in nearby counties-Alameda, Contra Costa, and San Joaquin-once the project has begun in earnest actual investment will extend to other Bay Area counties, particularly Santa Clara County, which has an extremely heavy concentration of high-technology firms.

To the extent that investment is captured within the San Francisco Bay Area, more economic benefits may be generated within the region, as the suppler community works interactively to provide necessary NIF inputs. That is, NIF investment will bounce around between the web of regional input suppliers, and add to other like investment activity in the area. This agglomeration of suppliers and purchasers enables a region to become more competitive and productive. Concentrated investment can induce economies of scale both for production and the transfer of ideas and technological innovations. High-technology concentration in Silicon Valley, and wineries in Napa Valley, represent two cases in which agglomeration has served to create world-class industries. In this vein it is important to note that the RIMS employment calculations do not capture the agglomeration effect, and as a result may under-estimate actual employment generated by NIF investment.

Table 1

Geographic Distribution of NIF Investment (Source: LLNL)

\begin{tabular}{|l|c|}
\hline Key NIF Components & $\begin{array}{c}\text { Percentage of Investment Spent } \\
\text { in SF Bay Area }\end{array}$ \\
\hline Project Office & $100 \%$ \\
\hline Site and Conventional Facilities & $100 \%$ \\
\hline Laser & $52 \%$ \\
\hline Target Area & $50 \%$ \\
\hline Integrated Computer Control & $50 \%$ \\
\hline Optical Components & $29 \%$ \\
\hline Total Project & $54 \%$ \\
\hline
\end{tabular}


One particular type of regional agglomeration to which the NIF may contribute relates to the high technology construction sector. The high concentration of sophisticated construction employment supported by the NIF in the San Francisco Bay Area will provide synergies with the existing high-technological fabrication sector already thriving in the region. As is well-known, the San Francisco Bay Area is home to a large number of hightech companies which require advanced construction, such as clean rooms, extra security, and unique electrical and water systems. NIF construction provides another impetus to support continued activity by these firms and to develop greater expertise to export services to other states and nations.

NIF-Induced Employment. Somewhat different employment estimates are presented in the various NIF documents sponsored by LLNL, Argonne, and the U.S. Department of Energy. This is because annual expenditure assumptions vary somewhat depending on actual project pace and congressional appropriations. The estimates contained herein reflect capital and operating expenditure data contained in the NIF CDR. Although more recent information is available, it is unlikely that current updates would significantly alter these employment estimates.

Table 2 displays estimated direct and indirect employment engendered during the NIF's peak construction phase. As also indicated in Figure 3, total employment is expected to peak in FY 1999, when approximately 2,680 jobs will be created in the San Francisco Bay Area and another about 3,485 jobs will be supported outside the region. 
Table 2

Regional and National Employment Engendered by the NIF (Source: Argonne)

\begin{tabular}{|l|c|c|}
\hline & $\begin{array}{c}\text { Construction Peak } \\
\text { Employment, FY1999 }\end{array}$ & $\begin{array}{c}\text { Annual Operating } \\
\text { Employment, Post-FY2002 }\end{array}$ \\
\hline Direct Jobs & 500 & 330 \\
\hline $\begin{array}{l}\text { Off-site Jobs (direct, } \\
\text { indirect and induced) }\end{array}$ & 5,670 & 1,220 \\
\hline $\begin{array}{l}\text { Total Direct, Indirect and } \\
\text { Induced Jobs }\end{array}$ & 6,165 & 1,550 \\
\hline $\begin{array}{l}\text { Total Jobs-San } \\
\text { Francisco Bay Area }\end{array}$ & 2,870 & 890 \\
\hline $\begin{array}{l}\text { Total Jobs-Outside San } \\
\text { Francisco Bay Area }\end{array}$ & 3,485 & 650 \\
\hline
\end{tabular}

NIF Wages. Figure 4 displays estimated job earnings induced by the NIF over time. As expected, the figure indicates a similar time pattern as the employment graph. Although more than half of the NIF investment will be related to manufacturing purchases, most of the NIF jobs will be associated with construction, including onsite construction managers, workers, electricians, and specialty engineers. While providing middle-income wages, $\$ 35,000$ to $\$ 45,000$ a year construction jobs tend to have lower earnings than manufacturing employment. As a result, dollars expended on construction creates more jobs than the same investment in manufactured products. However, the project will also demand the services of design engineers and other highly skilled professionals who tend to garner higher wages. For example, the average salary for a design engineer is approximately $\$ 65,000$. Based on U.S. Census data, the range of wage levels to be supported by the NIF are illustrated in Table 3 . 
Figure 3 Additional Employment Created by NIF Construction Within and Outside S.F Bay Area

(FY 1996-2002)

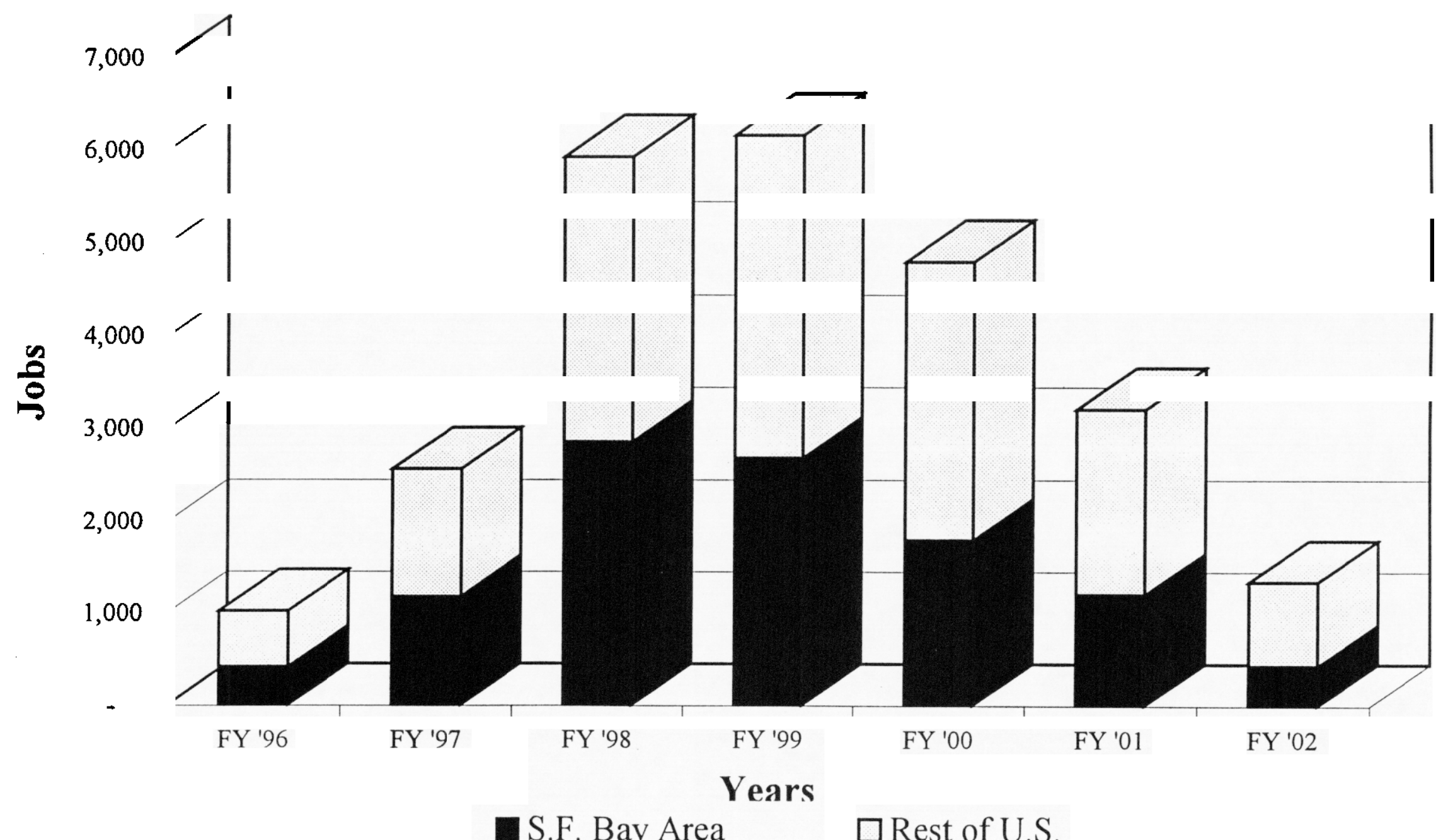


Figure 4

\section{Job Earnings Induced by NIF (in millions)}

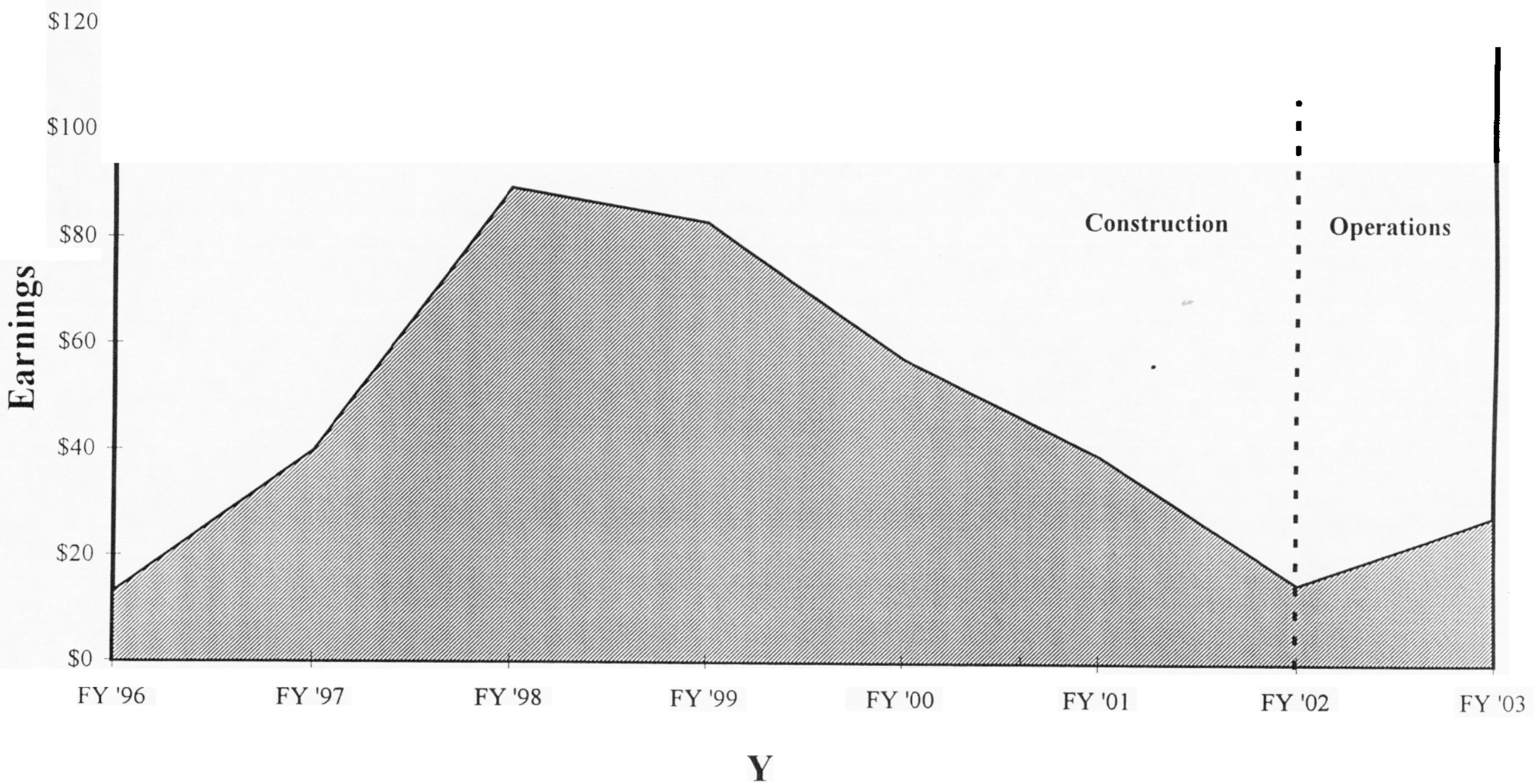


Table 3

Typical NIF Jobs and Salaries

(Source: U.S Census)

\begin{tabular}{|l|c|}
\hline Employment Category & Average Salary per Worker \\
\hline Electric Utility Construction & $\$ 45,160$ \\
\hline Electric Utility Maintenance & $\$ 28,401$ \\
\hline Industrial Chemist & $\$ 42,695$ \\
\hline Special Industrial Machinist & $\$ 86,504$ \\
\hline Industrial and Commercial Machinist & $\$ 33.434$ \\
\hline Electrician & $\$ 34,257$ \\
\hline Laboratory Instruments & $\$ 30,167$ \\
\hline
\end{tabular}

It is important to note that while projects such as housing construction may directly employ a greater number of workers per dollar invested than a project such as the NIF, the NIF will generate more overall economic wealth because it produces more economic value. For example, the gross domestic product (GDP) created by service industries is approximately $\$ 34,000$ per employee, compared with $\$ 62,000$ for the manufacturing sector. High technology jobs, such as the precision machine parts required by the NIF, can generate $\$ 82,000$ of GDP per employee, 140 percent higher than a typical service sector worker. In other words, NIF investment will contribute to overall economic growth because of the value generated by the facility's high-wage, high-skill jobs. Construction of a housing development does not deliver benefits of this scale.

Almost all of the construction work will be done by private sector firms. Approximately one-fifth of the employment created during the construction phase will consist of on- and offsite scientists, design and electrical engineers, and maintenance and repair workers. These jobs will be supported by a mix of employers, including private firms, LLNL, and other public sector organizations.

\section{Employment Estimates: Operational Phase}

Construction-related employment will decline after FY 1998, decreasing to zero once the project is completed in FY 2002. However, after the construction phase is over full NIF operations will be initiated. Beginning in FY 2003 NIF operations will support 895 direct and indirect jobs in the San Francisco Bay Area annually-based on the same definitions of direct and indirect presented earlier-of which 330 represent full-time positions at the Lab. Another 650 total jobs will be created outside the region related to procurement activity, and spending by those employed on-site. Table 2 displays summary data on direct 
and indirect employment induced by the NIF.

\section{Summary}

As currently proposed, over one billion dollars will be invested to create and operate the NIF over the next seven years. Over half of this investment will be expended to develop and purchase sophisticated equipment at firms located throughout the country. At its peak, NIF construction will create 2,680 jobs in the San Francisco Bay Area, and another 3,485 jobs outside the region. Most of these jobs will pay a middle-class wage,. $\$ 35,000$ to $\$ 45,000$ annually with some higher-paying professional and technical positions also created. After the NIF is fully operational, it will create 330 direct jobs and 1,220 indirect jobs.

NIF construction and operation will create a modest number of new jobs within the region. More significantly, these will be good jobs-the type of employment which enables families to purchase homes and send their children to college. These high-value jobs create a larger ripple effect through the economy than lower-value service sector or construction employment. In addition, NIF investment will help sustain the San Francisco Bay Area's concentration of high-technology fabrication firms, thereby increasing this sector's productivity and ability to export to other states and nations. 


\section{TECHNOLOGY AND THE ECONOMY}

The impact of technology, and in a larger sense, innovation, has not been well integrated into traditional economic theory because it is very difficult to establish analytical models that can easily relate the causal relationship between innovation and specific outcomes. In fact, technological innovation often works its way through the economy in very different patterns, depending on the nature of the technology itself, the sectors into which it is introduced, and the process or mechanism by which the technology is transferred from the initial development source to other users. As a result, while it may be possible to understand the general nature of the impacts that can be derived from technological innovation, it is not possible to quantify the precise magnitude and timing of such impacts. This section uses background information on the general role of technology in creating economic growth and an overview of the role the DOE National Laboratories have played in developing new technology to develop assumptions about the broad areas where NIF is likely to impact the economy.

\section{Technomics: The Role of Technology in Economic Growth}

It is generally acknowledged that the health of the U.S. economy is dependent on continuing innovation and diffusion of new technologies. While classical economic theory emphasized two key factors of production-capital and labor-there is growing recognition that technological innovation is perhaps the dominant factor in economic growth. In fact, many studies have concluded that advances in knowledge account for almost half of total economic growth.

Although traditional economists understood that technology played a role in economic growth, they viewed it as an exogenous factor which was random in nature and therefore impossible to analyze. Furthermore, the relatively fixed nature of capital and labor led traditional economists to believe that there were limits to growth, i.e., that the application of increasing quantities of capital or labor would inevitably yield diminishing returns. The paradox, particularly since World War II, has been that actual economic conditions have exhibited a much greater capacity for growth than implied by traditional economic theory.

More recent economic theory suggests that technological innovation plays an essential role in economic development and must be treated as a distinct factor with as much influence over economic outcomes as capital and labor. Dr. Paul Romer of the Hoover Institution has proposed a New Growth Theory which states that technological innovation may actually result in increasing returns because it can raise return on investment. According to Romer, investment in science and technology (i.e., research and development) expands an economy's knowledge base which in turn stimulates competitive pressure for more investment, thus producing an upward spiral of continuing economic growth. 
Technological innovation refers both to the development of more sophisticated hardware (e.g., the invention of the semiconductor) and the creation of greater knowledge and ideas (i.e., the discovery of DNA). Innovation encompasses everything from advanced agricultural techniques to computer software to management techniques that encourage worker productivity and creativity. But in order to effectively influence economic growth, technological innovation must consist of both depth-the advancement itself-and breadth-the dissemination and adoption of the advancement to relevant areas of the economy.

Technological innovation engenders economic benefits that are often overlooked or taken for granted such as increased national income and output, an improved trading position relative to foreign competitors, and the attendant political and economic influence that results from technological leadership. Technological progress leads to tangible improvements in goods and services (for example, on-line banking), and to less tangible, but highly valuable improvements such as increased knowledge. In fact, ideas-as embodied in software, entertainment, and consulting services-have been a significant factor in the recent growth in U.S. exports. Given the link between technology and economic prosperity, an increased emphasis on knowledge development implies a permanent change in the rate of discovery and economic growth.

Rationale for Public Sector Investment in Technology. Like the more classical distinctions of capital and labor, knowledge is a factor of production which has to be paid for by forgoing current consumption. Societies have to invest in knowledge in the same way they invest in machines. However, despite the importance of technological advancements to the health of the nation's economy, there are three primary factors which encourage less than optimal private sector investment in research and development.

1. Long lag time. There can be a long lag time between initial investment in technology and resulting benefits. This lag can be from several years to two decades or more. Corporations, particularly publicly-held organizations which must respond to stockholders' short-term demand for profits, frequently cannot justify investments which do not rapidly produce tangible benefits.

2. Research successes and failures. Investment in research will result in both successes-technologies for which there is market or social demand-and failures-technologies which are scientifically feasible but economically infeasible. As a result, firms face significant financial risks when investing in innovation. Large firms may be able to spread these risks across a portfolio of projects, thereby encouraging outcomes which on average provide net benefits. However, many firms have inadequate access to necessary resources, and cannot afford the risks associated with research investments. In the last few years, large U.S. companies with large R \& D departments have been cutting back drastically. 
3. Societal benefits. Technology investment appears to result in societal benefits that can be far greater-as much as twice as high, or higher-than the returns that an individual firm is able to capture through the market. For example, the "spill-over" effects associated with the development of fusion energy may include significant reductions in polluting air emissions, a societal benefit that may not be fully captured by any private party.

Taken together, these three factors provide an important justification for public sector investment in research and development. This investment can take various forms, including support for academic training in the sciences, grants for basic and applied research, and the pursuit of scientific projects which are likely to advance particular scientific disciplines. Every form of public sector investment in research and development has its value, and its limitations. For example, university research in the U.S. has been of enormous value in the development of semiconductor technology, biotechnology, and laser technology. However, aspects of these technologies have advanced to such a point that they must be addressed at a higher level of intensity and continuity than can be provided in a university environment. Therefore, it is necessary for the U.S. to support other avenues of advanced R\&D, such as at the National Labs.

Methods for Estimating the Economic Impacts of Technology. It is extremely difficult to accurately estimate the economic impacts of future technological investment and innovation, both at the macro (economy-wide) and micro (project-specific) levels. This is because technological progress does not follow a straight line. Rather, for most of the technologies whose development has been studied in detail, progress proceeded through a lengthy, complex process. For example, when AT\&T first invented the laser it could not envision any strong particular purpose for the device in the communications industry. However, successive generations of the laser have turned out to have a wide range of applications within and outside the telephone system. In fact, all current and future telephone systems are laser based. The laser has greatly influenced such fields as physics, physical chemistry, and has revitalized the field of optics.

Because the precise outcomes of future technological innovation are difficult to accurately estimate, most studies of the economic benefits of innovation are based on retrospective reviews. That is, analysts trace the implications of nearly completed or successful innovations through the economy. However, in the case of emerging, pre-competitive technologies it is very difficult to accurately predict either the nature or timing of potential economic benefits. But once a new technology does begin to be established, its adoption tends to follow an S-shaped pattern with time, where market penetration is slow initially, but then takes off rapidly once a critical level of acceptance has been reached. 


\section{The National Laboratories and the Economy}

The DOE administers three weapons laboratories: Lawrence Livermore National Laboratory (LLNL), Sandia National Laboratory, and Los Alamos National Laboratory. Along with university funded research and private sector $R \& D$, the National Labs are a key component of the United States' research infrastructure. Although the three weapons labs have different areas of expertise, they are linked by joint research in nuclear weapons. Because the labs are the direct descendants of the Manhattan project initiated during World War II to create the atomic bomb, nuclear-related research has remained the principal focus of the labs for the past 50 years. Because the scope of this research effort is so broad and so important to the national interest, the labs have been able to assemble some of the best research scientists in the world into uniquely configured interdisciplinary working teams.

During the cold war era the need for such weapons research was widely accepted as necessary to national security and therefore received a high degree of financial as well as social and political support. During this time period, which extended from post-World War II through the early 1980s, the National Labs, including LLNL, were somewhat isolated from other U.S. academic and industry research efforts due to the sensitivity of weapons-related research. Scientists from the labs published research results, participated in conferences, served on external review panels, and had some interchange with university and industry scientists and engineers who had security clearances. However, in general there was not a full free flow of information or communication between the labs and the rest of the country's research community.

During the 1980s, even before the break up of the Soviet Union, there was a significant shift in this country's position in terms of geopolitical conflict and economic competition. By the late 1970 s and early 1980 s America could no longer maintain its traditional postWorld War II role as world leader merely by having the strongest standing military force. Instead, a new world order was developing, defined in terms of economic rather than military hegemony, and the U.S. realized that the driving force behind economic powerhouses such as Japan and Germany was technological innovation.

Many of the key technology sectors in the U.S., including computer science, semiconductors, software and aerospace, were originally developed with significant financial support from the Department of Defense (DOD). But as these technologies matured, and found outlets in the civilian market, the proportion of research and development dollars contributed by the military began to account for an ever diminishing proportion of total R\&D investment, and military procurement ceased to be the driving force behind much of the technological innovation in the U.S. At the same time there was increasing interest in stimulating R\&D activity in order to ensure that the U.S. economy would remain competitive in a changing global environment. This, in part, led to a decision by the U.S. Congress to support collaborative relationships between public sector research initiatives, such as those at the labs, and private industry. Along with other changes in federal policy, including changes in intellectual property rights laws, the BayhDole Patent and Trademark Amendments Act of 1980 allowed the labs, for the first time in 
their 40 year history, to grant licenses to private businesses, non-profit institutions, and universities for patents developed from research funded with federal money.

The Bayh-Dole Act was followed by the Federal Technology Transfer Act of 1986, which allowed certain federal research facilities to enter into cooperative research agreements with industry to jointly develop technologies being created by federally funded research efforts. A 1989 amendment allowed the DOE labs to participate in such cooperative agreements with industry.

Although Congress's technology transfer initiatives were primarily targeted at DOD and Department of Commerce programs that had previously funded much of the nation's defense-related advanced scientific research, the DOE labs were also incorporated into this new policy push toward re-examining federally funded research activities to be sure they included "dual use." The decision to support dual use research activities was based on the desire to both satisfy defense requirements and to create technologies, products, or manufacturing systems that could also be applicable to civilian needs.

This new policy in favor of dual use had two impacts on the labs. One was that the basic mission of the DOE labs, which had historically centered on weapons research, was called into question. Many people thought that the labs should be either abolished, or that their resources should be used as a technology breeding program to supply private industry with new technological innovations. The second impact on the Lab was that for the first time Lab scientists began to work directly with industry on research and development activities. Between 1989 and 1996, LLNL alone entered into over 237 Cooperative Research and Development Agreements (CRADAs) with private companies. These agreements, which allowed the private sector partners new intellectual property rights to the results of the research and often provided government funding to match funds contributed by the private industry, have become one of the primary vehicles for transferring technology out of the labs.

Both the larger debate around the DOE labs' mission in light of the end of the cold war and the CRADA experience led policy makers to understand that the labs were not well equipped to serve a new mission solely as technology breeding programs. Such a mission lacked focus and commercial responsiveness, and it was not generally well suited to the strengths of Lab personnel. Therefore, such an approach would very likely yield limited results relative to the level of investment necessary to have any significant impact on the U.S. economy.

In September 1995, President Clinton announced that the DOE labs would continue their core mission, focusing on the reduction of global nuclear danger. In this capacity, LLNL in particular "... see[s] these areas-global security, energy, environment, and bioscienceas the principal elements of our future mission." (Institutional Plan FY 1996-2001, Lawrence National Laboratory, University of California, October 1995). While this decision clarified that the labs would not have a significant shift in their basic mission, it did not preclude the continuation of ongoing collaborative research relationships with 
private industry. In reality, the CRADAs and other technology transfer mechanisms have provided a valuable insight into the unique resources that the labs have to offer to private industry, and some of the benefits that have accrued to both to industry and to the labs themselves from this collaboration, including the following:

Leverage. The U.S. invests billions of dollars annually to support research activities at the labs. By allowing the labs to share the results of their research with private industry, and encouraging more research investment by private industry, the U.S. is able to leverage its research dollars to gain an increased level of expenditures from the private sector.

Resources. The Labs represent a distinctly unique combination of resources, both in terms of broad multi-disciplinary research teams and physical resources that are not available either from the private sector or through university research facilities. State-of-the-art computation facilities allow for significant modeling and optimization efforts. As a result the labs can provide assistance in the predevelopment of complex technologies that are beyond the current capabilities of private sector firms.

Timing. Research and development departments within private firms are under enormous pressure to work within a very tight product cycle and help produce near-term profits. As the costs for R\&D associated with new product development have soared, private industry has generally not been able to bear the high capital costs associated with long-term R\&D while simultaneously battling current foreign and domestic competition. On the other hand, the labs have the ability to undertake complex multiyear research projects that may ultimately benefit both their own work as well as that of private industry.

Co-development. Typically, discussions about technology transfer and the labs assume that the labs are producing technologies that are fully developed and can be readily integrated into other products. However, experience over the past several years shows that this is not the case. Technologies developed by the labs can be very promising to private industry, but they are typically too immature for rapid commercial application and require additional investment in research and development from private industry. To facilitate the process of technology transfer, the labs must continue to play a role, offering the technical expertise of its scientists and the physical infrastructure of its equipment and facilities.

Diversified R\&D Portfolio. As the earlier discussion on the role of technology in the economy indicates, there is an ongoing need for the U.S. to produce technological innovation if its economy is to continue to grow. While some, if not most, of this innovation will be produced through privately funded research and development efforts, the labs offer a resource that can complement these private efforts, and thus leverage the impact of both public and private investment. By utilizing the diverse range of research opportunities in this country, including the 
labs, the U.S. will have the best chance of maintaining its position of worldwide technological leadership.

Contributions to U.S. Knowledge Base. Research citations, patents, licenses, and $R \& D 100$ Awards all represent ways in which the labs have contributed to the overall knowledge base in the U.S.. In the past five years alone, LLNL research has been cited 5,000 times in research literature, the Lab has entered into approximately 30 license agreements, has been issued 230 patents, and has received $67 R \& D 100$ Awards from $R \& D$ Magazine.

More Efficient Lab Research. Although the labs have been leaders of cutting edge scientific research in the U.S., they also work on projects that in some ways lead, but are also parallel to, research and development efforts in private industry. In the past, when the parts of the labs were required to work in isolation because of security issues, they missed the opportunity of collaborating with other research organizations and having access to their developments. Today, because they are able to work more directly with industry, the labs have been better able to integrate the best information available from these other R\&D sources, thus increasing their own effectiveness.

\section{NIF and the Economy}

As the above discussion of "technomics" and the role of the National Labs in the economy demonstrates, scientific research has an important impact on economic growth. However, the magnitude of this impact, the timing in which impacts occur, and the direct beneficiaries of such impacts, are very difficult to predict. Furthermore, benefits from research are often intangible. For example, research does not always yield successful results, but failures can sometimes render as much useful information, if not more, than success.

The literature on the role of technology in economic growth, a review of the National Lab's general experience with technology transfer, and discussions with academic researchers, LLNL personnel, and industry experts, indicate that there are four areas where new technologies associated with the NIF are likely to have an impact. These four include:

- Impacts on the economy

- Impacts on science and technology

- Impacts on quality of life

- Impacts on the Lab

Impacts on the economy are usually defined in quantitative terms such as potential revenues, market share, number of firms, number of jobs, level of investment in new capital equipment and infrastructure. However, economic impacts can also be qualitative: improved competitive position, supply channels that are more reliable, joint research efforts that are more 
cost-effective, and so on. Ultimately, both quantitative and qualitative impacts will be reflected in changes in gross domestic product (GDP) through productivity gains, quality improvements, and lower costs.

It is important to note that these economic impacts will vary in different regions of the country. While geographic distribution of economic impacts can be difficult to predict, it is important to make this link so that policy makers can understand how to capture or further enhance any economic benefits associated with technological innovation. However, the level of analysis required to better understand these linkages, especially with respect to the NIF, is beyond the scope of this report.

Impacts on science and technology are the most basic impacts resulting from a major research undertaking such as the NIF. Because this facility will be larger and more powerful than any other laser in the world, the ongoing research results it renders will greatly enrich the basic core of universal scientific knowledge. Furthermore, history demonstrates that commercializing a technological innovation is not a simple, linear process. Indeed, R\&D efforts often generate their own feedback loop as the need to improve a product or process can stimulate further basic scientific research.

Impacts on quality of life result from technological innovations that save lives, preserve the environment, or raise living standards. Examples include new automotive safety systems, medical diagnostic equipment, and cheaper and more reliable telecommunications systems. While such impacts are generally difficult to quantify-it is hard to quantify the value of better disease detection-they are often pervasive and therefore are included in this analysis.

Impacts on the Lab is a discussion of LLNL's role in developing the technology, and the value of the Lab in the R\&D process. For example, in many cases the Lab has served as a focal point for companies with common interests to come together. As it has become more difficult for individual firms to conduct broad research efforts, the Lab allows a wide assortment of firms to work in various areas and share the Lab's resources. By giving private industry a cost-effective way to explore high-risk technologies, the Lab helps U.S. companies to compete globally. The Lab itself can benefit from this process as many of the technologies that are spun off from the laser program may ultimately result in products that are critical to the Lab's core mission of science-based stockpile stewardship.

The two case studies discussed in the next chapter provide an opportunity for understanding in greater detail how technological innovation generated from the NIF could 
have more specific impacts within these four broad impact categories. An additional six technologies have been profiled in Appendix A, but because these technologies are more nascent, their impacts are less well defined than for the technologies that are currently entering the commercialization process. 


\section{LASER RELATED TECHNOLOGY CASE STUDIES}

Lawrence Livermore National Laboratory's (LLNL) 25 years of experience in designing, constructing, and operating state-of-the-art laser systems offers a selection of excellent case studies which demonstrate how technologies developed to assist the Lab's inertial confinement fusion (ICF) program have had "spin-off" benefits to private industry, as well as "spin-on" benefits to the Lab itself. Although the Lab has only in recent years been formally authorized to participate in technology transfer opportunities, a surprising number of the Lab's ICF program technologies have attracted interest from the private sector.

As with previous ICF program research efforts, the National Ignition Facility (NIF) is expected to generate new discoveries and new technologies whose impact will be felt far beyond the Lab. Because it is difficult to predict what specific new technological innovations resulting from NIF will be, this section examines a sample of two recent technologies that have come out of earlier research efforts associated with the Lab's ICF program: extreme ultraviolet lithography (EUV) and micropower impulse radar (MIR). Another six technologies that also have strong potential for commercialization are presented in Appendix A. Table 4 presents a summary of all eight technologies profiled in this report. These technologies have been selected primarily because they have potential commercial application, although some are more readily commercialize-able than others. Each case study examines the technology's links to the laser program and potential industries that may be served.

In addressing the potential impacts of EUV lithography and MIR technology, this report focuses on the four impact categories discussed in Chapter III:

- Impacts on the economy

- Impacts on science and technology

- Impacts on quality of life

- Impacts on the Lab.

To provide a sense of the magnitude of their potential impact, particular emphasis has been placed on identifying the overall size of the industrial sectors that could be affected by these technologies. However, because these technologies are still primarily in the research or early development phases, it is not possible to quantify the size of each impact. 
Table 4

Laser Related Technology Case Studies

\begin{tabular}{|c|c|}
\hline Technology & Description \\
\hline $\begin{array}{l}\text { 1. Extreme ultraviolet lithography } \\
\text { (EUV) }\end{array}$ & $\begin{array}{l}\text { A key technology in the semiconductor } \\
\text { industry. EUV will allow semiconductor } \\
\text { manufacturers to continue to fit more } \\
\text { circuits on a microchip. }\end{array}$ \\
\hline $\begin{array}{l}\text { 2. Micropower impulse radar } \\
\text { (MIR) }\end{array}$ & $\begin{array}{l}\text { MIR is a powerful, low cost, short pulse, } \\
\text { radar technology with applications ranging } \\
\text { from medical equipment to auto safety } \\
\text { devices. }\end{array}$ \\
\hline 3. Advanced precision optics & $\begin{array}{l}\text { Advanced precision optics are fundamental } \\
\text { components that allow the Nova and NIF } \\
\text { lasers to function. Applications range from } \\
\text { satellites to precision manufacturing } \\
\text { equipment. }\end{array}$ \\
\hline 4. Advanced health care technologies & $\begin{array}{l}\text { The application of laser program technology } \\
\text { to medicine in order to simultaneously } \\
\text { reduce the cost of medical procedures, and } \\
\text { reduce physical stress to medical patients. }\end{array}$ \\
\hline 5. Field emission displays & $\begin{array}{l}\text { FED utilizes advanced optical } \\
\text { interferometer techniques to } \\
\text { lithographically create the tips that serve as } \\
\text { point light emitters in a flat panel display. }\end{array}$ \\
\hline 6. High density magnetic storage & $\begin{array}{l}\text { A new technology to improve computer } \\
\text { performance by increasing hard disk } \\
\text { density, i.e., increasing the number of bits } \\
\text { of data storage per inch of disk track. }\end{array}$ \\
\hline 7. Micro optics & $\begin{array}{l}\text { The production of ultrathin lenses that are } \\
\text { used for medical, commercial, and military } \\
\text { applications. }\end{array}$ \\
\hline 8. Laser material processing & $\begin{array}{l}\text { This technology utilizes very short pulse } \\
\text { lasers to effect new mechanisms in laser } \\
\text { materials processing that leads to precise } \\
\text { and non-splattering material removal. }\end{array}$ \\
\hline
\end{tabular}




\section{Extreme Ultraviolet Lithography}

Microlithography is the critical step in the semiconductor fabrication process where the pattern circuitry is laid out on the silicon wafers. This is a photographic process involving both film coatings and exposure to light. The size of the line-widths in these circuits is critical to the semiconductor industry, because there is a direct correspondence between the amount of circuitry that can be accommodated on a single chip, and the overall complexity of functions the chip can perform. Therefore, as demand increases for higher powered semiconductors, there is also continuing increased demand for smaller circuits.

Gordon Moore, who would later co-found Intel Corp. with Robert Noyce, wrote in 1965 that the number of transistors that could be put on a chip would double approximately every 18 months. "Moore's Law" recognized that because this doubling in density did not result in a commensurate increase in cost, the expense per transistor was greatly reduced. Thus began a cycle that would become the foundation of the semiconductor industry: advances in the computing power of semiconductor chips spurred the development of applications needing yet more power, which in turn stimulated the production of smaller and more powerful chips.

At the heart of this virtuous cycle within the semiconductor industry has been the ongoing ability to create lithographic and other manufacturing techniques that have allowed the industry to maintain this approximately 18 month cycle whereby the line-widths in the circuitry have been constantly reduced. Currently, a typical high-volume manufacturing operation produces chips with line geometries of approximately 0.5 -microns, although some state-of-the-art fabs have a 0.35 micron process (a fab is a semiconductor manufacturing plant). The long-term challenge facing semiconductor manufacturers is moving to larger wafers and smaller line geometries. According to a recent market outlook, by 2002 the U.S. semiconductor industry aims to be "positioned with a 0.18-micron process for use on 12-inch wafers." Two Japanese firms, Nikon and Canon, are the leading lithography equipment makers and, along with their U.S. counterparts, are avidly competing to produce the next breakthrough in this technology.

However, one of the major barriers to making this next breakthrough is the lithographic process itself. Standard manufacturing techniques currently rely upon optical light to etch the circuit patterns onto silicon wafers. But, optical light waves are wider than the size of the line geometries necessary to achieve ongoing advances in miniaturization, and therefore to support long-term growth of the semiconductor industry. The industry has been exploring multiple options for developing alternative lithographic processes utilizing non-optical light for many years. All of these technological solutions have very significant drawbacks or constraints that researchers are currently trying to resolve. Such research is imperative to the future success of the semiconductor industry, and therefore to the continued growth in the electronics industry, as well as for many other industries that use semiconductors, including everything from automobiles to medical instruments.

Extreme ultraviolet lithography (EUV) is one of the technologies the semiconductor industry is considering as an alternative to optical lithography. Although physicists and industry researchers 
have long recognized EUV lithography's theoretical potential, up until about 1988 the barriers to developing this technology were considered so significant that most research and development resources in the United States were primarily devoted to exploring other alternative light sources.

\section{EUV Lithography and the LLNL Laser Program}

To make EUV lithography viable for the semiconductor industry, multiple technical problems had to be resolved. Coincidentally, several of these same technological issues related directly to work going on in the laser program at LLNL.

LLNL's ten-beam Nova laser (named for brightly exploding stars) is the largest laser in the world and was constructed in order to conduct nuclear fusion research. Nova re-creates the fusion process by focusing up to 50 trillion watts of ultraviolet light for one billionth of a second on a small fuel capsule containing the hydrogen isotopes deuterium and tritium. During the billionth of a second, the laser beams compress and heat the deuterium and tritium, causing their nuclei to fuse and to release energy. In brief, when the Nova laser is fired, it creates infinitesimal stars that last for a billionth of a second. The NIF will essentially replicate this same process, but at a larger scale, and using different types of fuel capsules, or targets, with the hoped for result of creating inertial confinement fusion ignition, i.e., producing more energy than is delivered to the target.

Millions of measurements are made during the billionth of a second that each ICF experiment lasts. The process of recording these measurements is generally referred to as "diagnostics", i.e., the ability to capture the data created when the laser beams are directed at the fuel capsule, or target. In the early 1980s, the lab recognized that it needed to improve its diagnostic capabilities significantly to be able to capture more information about the spatial and temporal effects of the ICF experiments.

Lab researchers began to understand that X-ray diagnostics were an important tool for understanding ICF targets. ICF targets emit copious X-rays and those $\mathrm{X}$-rays can be used to tell scientists how the target is working. Therefore, LLNL developed an extensive expertise and infrastructure that was used to take sequential X-ray images of targets, measure amounts and spectra (energies) of X-rays, and many other measurements. In addition to measuring and characterizing the $\mathrm{X}$-rays emitted from a target, scientists began creating artificial X-ray sources by shining one of the Nova beamlines at a tiny bead of material to create a tiny burst of X-rays of a specific characteristic energy spread to use as a "backlighter"- - that is to shine the X-rays through the target and take X-ray pictures (like those done of a patient in a hospital) even when a specific target component itself is not emitting.

Another line of investigation for ICF combined X-ray diagnostics expertise with laser design expertise to produce the world's first X-ray laser-that is a coherent beam of light at EUV and Xray wavelengths rather than visible wavelengths. Such an instrument would have important implications for diagnostic measurements of ICF plasmas as well as spin-off applications in biomedical research. In developing the X-ray laser LLNL needed a capability to make X-ray mirrors that worked at "normal" incidence, i.e. the X-rays strike perpendicular to the surface rather 
that at a "grazing" or small incident angle as all previous X-ray diagnostics. To develop normal incidence X-ray mirrors LLNL learned how to deposit uniform surface layers of material that are only a few atoms thick. Another result of the research was the development of "diffractive" optical elements, i.e. thin optical components that do their job (focusing or steering) by means of the surface characteristics of the component rather than bulk properties like a thick focusing lens.

The development of the above capabilities for ICF research resulted in development of a unique infrastructure at LLNL that could be used for other purposes. The infrastructure consisted not only of the specific products of the research itself, e.g. normal incidence X-ray mirrors, but also of the expertise in understanding, controlling, and handling $X$-rays and of the instrumentation required to develop such diagnostics. For example, a new instrument had to be invented that could measure the uniformity and other characteristics of the atomic layers deposited.

At the time that these developments were being made, virtually nobody at the Lab gave any thought to their relevance or applicability to research and development within various U.S. industries. However, one scientist, who had recently received his Ph.D. from MIT and was familiar with the barriers confronting the semiconductor industry, did recognize that this research could help make EUV lithography a viable alternative to optical lithography, and that this could help overcome the semiconductor industry's major hurdle for enabling the miniaturization process to continue at the desired rate.

Based on his knowledge of industry's concerns plus his understanding of the Lab's capabilities, this scientist, Dr. Andrew Hawryluk, published a paper in 1988 describing the technological innovations achieved by the Lab, and explaining how these innovations were related to EUV lithography. Soon after he presented this paper, Dr. Hawryluk was approached by representatives from the former AT\&T to discuss the work in more detail. These discussions eventually expanded to include eight other companies and Sandia National Laboratory as well as LLNL. After three years of discussion, industry and the Lab formed the EUV Lithography Industrial Advisory Board whose members have contributed $\$ 75$ million through mid-1996 to pay for 50 percent of the costs of EUV lithography research (the other 50 percent has been funded by the Department of Energy). This group developed a three year work program to direct further research at the labs in this area, and to oversee and interact with the lab scientists on an ongoing basis.

In April 1996 a milestone review was conducted by the EUV Lithography Industrial Advisory Board which found that LLNL has successfully completed its research milestones and is ready to move into the development phase. This approval from the IAB is a major achievement because it demonstrates that private sector firms with the most critical interest in finding a solution to the limitations of current optical lithography endorse the direction of LLNL's EUV project. The Lab and its industry partners will now focus on building a feasibility machine to serve as a test bed for technical solutions that have come out of the research phase. This feasibility machine will allow the Lab and industry to reduce the remaining uncertainties in critical EUV technologies. If the three-year feasibility machine program proves successful, the project will move forward to a sixyear alpha and beta machine program, leading to the development of a production machine by 2005. 
An analysis of the impacts EUV lithography will have are described below.

\section{Impacts on the Economy}

Assuming that EUV lithography will provide at least some, if not a critical piece of the solution to critical technical hurdles facing the semiconductor industry, this technology will have a very significant impact on three sectors of the economy: semiconductors, semiconductor equipment manufacturing, and the electronics industry as a whole. The first two currently account for $\$ 155$ billion and $\$ 30$ billion in worldwide sales respectively. The semiconductor market alone is expected to increase by over 40 percent by 1999 . Worldwide, the electronics industry now accounts for $\$ 700$ billion is sales, and is expected to reach $\$ 1.1$ trillion by 1999 . While there are no accurate estimates as to the growth curves of any of these industries beyond the next three years, it is certain that currently projected growth rates can only be maintained if certain technical barriers, including optical lithography are overcome. Without EUV lithography three critical sectors in the world economy could suffer from severe setbacks in growth. While there are other alternative technologies to optical lithography currently under consideration, EUV appears, at this time, to have the best near term potential.

During a panel discussion held with semiconductor industry experts regarding the impacts of EUV lithography, participants expressed concern regarding the future of the U.S. in this competitive, dynamic, and attractive market. A representative from a U.S. semiconductor manufacturer observed,

"If you roll the clock back to a decade ago when the Japanese semiconductor market was growing and we were shrinking, it was a foregone conclusion that the U.S. would become the minority stakeholder in the semiconductor industry. Fortunately, through a lot of effort by Sematech and SIA [Semiconductor Industry Association], and maybe a little good luck, that trend has been reversed. The reemergence of the U.S. in this market has had a dramatic impact on the U.S. economy for an awful lot of industries that are not directly involved."

Given this environment, industry experts feel that in order for U.S. semiconductor companies to continue to compete globally, private and public resources must continue to be invested in the development of advanced lithography techniques. Moreover, these experts indicated that EUV lithography has very good promise for helping the industry maintain its current growth curve.

The discussion below provides a more detailed description of the three primary sectors that will be impacted by the technological improvements offered by EUV lithography.

Semiconductor Market Segments. The three largest segments of the semiconductor market are memory chips, microcomponents, and logic chips. 
Memory Chips. Memories are the largest market segment ( $\$ 32$ billion worldwide), mainly because of the growth of the personal computer (PC) industry and the increased memory requirements of the newest machines. Computer networking and digital video applications are also heavy users of memory chips. Makers of DRAM chips, the largest segment within the memory market, have historically introduced a new product generation every three years. Such a shift is currently underway as the market moves from 4 megabit (M-bit) to $16 \mathrm{M}$-bit DRAMS. While advances in miniaturization typically occur first in memory chips, commercial production of gigabit (1,000 M-bit) DRAM chips may be hindered by limitations in current optical lithography technology.

Production of DRAM chips is led by Japan (54 percent of the market) and other Asian suppliers (28 percent), while North American firms have 15 percent of the total world market. Japan's dominance has been attributed to its joint government/industry initiative that targeted the memory market in the mid-1970s. Through aggressive pricing and other competitive practices the Japanese succeeded in driving U.S. firms such as Advanced Micro Devices (AMD), Intel, Motorola, and National Semiconductor out of the DRAM market. Japan's determination to maintain its lead was clear at a 1995 industry conference where two Japanese suppliers demonstrated a 1 gigabit DRAM that will require sub-0.2micron line features. Japanese firms Hitachi and NEC are currently in the R\&D phase of a sub-0.2-micron manufacturing process.

In retrospect, some analysts view the U.S. exit from the DRAM market as a partial blessing in disguise because U.S. firms were removed from what has become a commodity market and were forced to invest in the development of innovative products such as microprocessors and logic chips, two classes of semiconductors that carry much higher profit margins.

Microcomponents. U.S. firms lead the microcomponent sector (microprocessors and microcontrollers) with 66 percent of the $\$ 24$ billion worldwide market. As with memory chips, growth is highly correlated with PC sales, although advances in microprocessors have also fueled the development of products such as fax machines, cellular phones, video cameras, and pen-based computers. Advances in microprocessor technology have delivered increased power at lower cost, and have made possible products that in the past would have been prohibitively expensive or technically infeasible. For example, a $\$ 2,000$ off-the-shelf PC in 1996 can perform tasks that two decades earlier would have required a multi-million dollar mainframe computer.

Logic Chips. The $\$ 18$ billion worldwide logic market is dominated by ASIC chips (application specific integrated circuits) which perform a distinct task and are designed in accordance to customer specifications. ASICs are required for specialized functions such as computer networking and digital video applications. While ASICs cost more to produce than off-the-shelf components, they also offer more computing power by integrating several functions into a single chip. Because only essential circuits are present, ASICs are inherently more dependable than generic chips. ASICs also fit the electronic 
industry's trend toward greater miniaturization as they reduce the number of chips needed in a system. While American firms make up five of the top 10 ASIC manufacturers, the U.S. and Japan have basically equivalent shares in this important market sectorapproximately 35 percent each.

Although it is inevitable that semiconductors will be integrated into a growing number of electronic devices, future applications are expected to require yet more sophisticated microcontrollers, microprocessors, and logic chips. However, this does not mean that the U.S. will necessarily retain its present position in the microcomponent and logic markets. Since Japan and other Asian countries are sizable exporters of electronic components, particularly of consumer electronic equipment, they have a strong incentive to develop their own capacity for microcomponents in order to reduce their dependence on U.S. producers. In any case, chip makers in both the U.S. and Japan must face the limitations of existing optical lithography technology as they seek to increase the number of circuits produced on each chip.

Outlook for the U.S. Semiconductor Industry. As with many technology sectors, the semiconductor industry can experience short-term volatility. However, the long-term outlook is believed to be favorable because of two positive trends: 1) the growth of the electronics industry; and 2) the growing number of semiconductors contained in electronic equipment.

In every economy across the spectrum, from the U.S. and Germany to India and Vietnam, sales of electronic equipment ranging from PCs, microwave ovens, cordless phones, cameras, fax machines, $C D$ players, etc., are constantly increasing. The Integrated Circuit Engineering Corp. (ICE), a research firm based in Scottsdale, Arizona, estimates that worldwide sales of electronic equipment will increase to $\$ 1.1$ trillion in 1999 (up from $\$ 700$ billion in 1996). Furthermore, ICE projects that the semiconductor content of electronic equipment will increase from 16 percent of the product's total value today, to 20 percent in 1999. This outlook is consistent with past trends; for example, in the PC market a high-end PC in 1983 contained $\$ 400$ worth of semiconductors while a high-end model in 1996 has $\$ 1,500$ worth. The combination of these two trends has led analysts to predict that worldwide semiconductor sales will top $\$ 213$ billion in 1999 , up from $\$ 155$ billion in 1995 .

The U.S. Semiconductor Equipment Industry. Semiconductor equipment is a $\$ 30$ billion market world wide. SEMI, the international trade association for the semiconductor equipment industry, has 1,800 member companies worldwide.

Competition with Japan. Japan's entry into the DRAM market in the mid-1970s had unanticipated consequences for U.S. semiconductor equipment firms. The global market share of U.S. stepper manufacturers declined throughout the 1980s as Japanese and Korean chip makers purchased most of their optical lithography equipment from Japanese firms. During this period, the U.S. market was weak because U.S. chip makers were 
recovering from a market downturn and were not investing in capital equipment. By the mid-80s when U.S. chip makers were expanding once again, Japanese stepper manufacturers were able to gain dominance of the U.S. optical lithography market by offering high quality, aggressively priced machines to U.S. chip makers.

Technological Dependence. While U.S. semiconductor manufacturers clearly benefited from high quality/low cost Japanese equipment, people inside the industry and in government were concerned by the U.S.'s growing reliance on Japanese technology for the manufacture of advanced components. Because U.S. and Japanese firms compete in both the chip and equipment markets, U.S. chip makers began to fear that they would not have the same access to state-of-the-art manufacturing equipment as their Japanese counterparts. In 1987 the National Academy of Science and Engineering issued a report expressing concern about U.S. dependence on Japanese technology, and concluded that Japan's ability to withhold advanced equipment from the U.S. market could potentially block U.S. chip makers from competing in the global semiconductor market. The report also pointed out that no individual chip maker or equipment supplier had the necessary resources to solve all the technical obstacles related to future chip generations, particularly the complex and expensive technologies involving highly advanced microlithography.

Sematech. Sematech (Semiconductor Manufacturing Technology) was formed in 1987 in response to these concerns. As an industry/government consortium, it functions primarily as a research organization that is focused on assisting American semiconductor and equipment companies to improve manufacturing technology and to overcome technological hurdles that face the industry. There is widespread agreement on the technical accomplishments of Sematech in such areas as process models and device structure design, technology simplification, and new wafer substrate materials. Furthermore, Sematech's National Technology Roadmap for Semiconductors has identified cost and technology challenges facing the semiconductor industry over the next 15 years and serves as a guide for research and development decisions by identifying potential options for achieving advances in integrated circuit technology. Although Sematech does not produce or sell products, its research benefits member companies who have provided 50 percent of the organization's budget (the other half has been federally funded).

Sematech's latest annual report points out that government return on investment in the consortium has been substantial. Industry has contributed $\$ 950$ million to Sematech since it's inception, compared to $\$ 819$ by the federal government. Over the same period, Sematech member companies have paid more than $\$ 37$ billion in federal, state, and local taxes. Beginning in 1997, federal funding of the consortium will cease and Sematech will be financed entirely by industry contributions.

Outlook for the U.S. Semiconductor Equipment Industry. Because of its dependence on the ability of chip makers to accurately forecast the semiconductor market, the semiconductor equipment business can be volatile, and is even more vulnerable to cyclical 
downturns than semiconductor manufacturers. In spite of the recent slowdown in the global semiconductor market (attributed to excess supply produced by new plant openings, and a miscalculation in expected $1996 \mathrm{PC}$ sales), the current glut is not viewed as a harbinger for the long term. Rather, equipment makers are anticipated to benefit from continued capital spending because each new chip generation (which appears approximately every three years) requires investment in new production, assembly and testing machinery. Another important factor is the industry's current shift from four- and six-inch wafers to eight- and 12-inch wafers. At the same time, the feature size of the circuitry has become smaller and the chip manufacturing industry must adopt increasingly sophisticated machinery in order to stay on the leading edge.

In 1970, 40 percent of the cost of a new fab was for equipment. By the 1980s equipment costs accounted for 55 percent of total fab costs, and today the number is nearly 70 percent. In 1968, Intel Corp.'s original factory cost $\$ 3$ million; by the 1980 s, the cost for a new fab was $\$ 250$ million, and by 1994 the cost was $\$ 1.8$ billion. Analysts predict that fab costs could reach $\$ 3$ billion each as the industry moves toward a sub- 0.2 micron manufacturing process.

Semiconductors and Electronics. Today, semiconductor chips are a $\$ 62$ billion annual market in the U.S., and a $\$ 155$ billion annual market worldwide. The U.S. exported $\$ 32$ billion of semiconductors in 1995, nearly equaling our aerospace exports. Semiconductors are an enabling technology for the $\$ 700$ billion worldwide electronics market. U.S. semiconductor firms employ 290,000 workers, or 11 percent of all workers in the electronics industry. To offer some perspective, the electronics industry is the largest basic industry in the U.S. with $\$ 424$ billion in sales, and $\$ 123$ million in exports. With 2.6 million workers, the electronics industry employs more Americans than the auto, aerospace, and steel industries combined.

\section{Impacts on Science and Technology}

Science-Based Technology. Industry experts agree that LLNL's multi-disciplinary science-based research teams and technical infrastructure are unique resources that have been critical to the development of EUV. The use of basic science in such research is one of the most important defining features of technologies being generated by the Labs, and is what enabled the breakthroughs on EUV lithography. Furthermore, the Lab's vigilance and flexibility has helped it to identify ways to apply mission-oriented research to the commercial sector. Given that an LLNL scientist was the first to make a connection between the Lab's laser research and the needs of the semiconductor industry, it is unlikely that the EUV project would ever have been initiated without the Lab. According a lithography expert from a U.S. chip making firm, "The technology we find at LLNL is well beyond anything available in the outside world. Their work on EUV's optics is very advanced and is not available anywhere else."

Extended Time Horizons. One of the greatest advantages the Lab has over private industry is that it is able to undertake research projects with longer time horizons. The excessive costs associated with new product development have made it increasingly difficult for private sector 
firms to bear the high costs of long-term R\&D projects while simultaneously battling foreign and domestic competition. Through CRADAs, licenses, and other agreements, the Lab offers industry an option for fully bearing or sometimes sharing the costs of developing new technologies.

Increased Research Portfolio. By pursuing EUV development, in tandem with research in ebeam and X-ray lithography, the U.S. semiconductor industry is investing in a portfolio of techniques, one of which will ultimately overcome the limits of current optical lithography. According to a representative from a U.S. semiconductor equipment supplier,

"Lithography is going to be the 21 st century Moore milling machine. It will be the means by which we build a great many different machines that will be used in the next century. There are already many applications for lithography, for example, thin film heads-the little device that records data on a hard disk. Lithography is used to make flat panel displays, which will be ubiquitous before too long, as well as new types of micro-machined sensors."

If LLNL's EUV project results in a commercially viable EUV lithography machine, it will allow the semiconductor industry to continue to achieve "Moore's Law"-driven productivity gains, and will free U.S. chip makers from their dependence on foreign suppliers for state-of-the-art manufacturing equipment. In addition to the resulting economic benefits, the U.S. semiconductor industry will also enjoy continued technological growth as advancements in lithography lead to the development of ever more powerful, complex, miniature devices.

\section{Impacts on Quality of Life}

Assuming that EUV is a viable alternative to optical lithography, the technological changes that this will engender will be pervasive throughout society. The advances in electronics through miniaturization will likely lead to new scientific discoveries that rely upon massive computing power. In addition, small electronic components will be cheaper and easier to integrated into many other types of products.

One example where EUV could have a very significant impact on quality of life is in the elimination of nuclear testing and the adoption of new policies for science-based stockpile stewardship. This program has led the Department of Energy to pursue the development of computer systems that can simulate nuclear explosions, which requires extremely fast and powerful computers. Advanced lithography is crucial to the success of DOE's supercomputing program as the requirements for processing power move from gigaflops (billion instructions per second) to teraflops (trillion instructions per second) to petaflops ( $10^{15}$ instructions per second).

Because EUV lithography is critical to the development of advanced computer simulation systems that underlie science-based stockpile stewardship, one of the greatest impact EUV could have in terms of quality of life is its essential role in ending the need for nuclear weapons testing. While it is expected that EUV will allow the development of future generations of electronic equipment ranging from advanced medical diagnostic tools to cheap and powerful telecommunications 
devices, industry experts agree that most future applications incorporating EUV technology have not yet been fully conceived.

\section{Impacts on the Lab}

The Lab itself has benefited from the process of developing EUV lithography by gaining greater awareness of the commercial, technological, and business issues faced by its private industry partners. For example, the capital intensive nature of the semiconductor industry has made it essential for the Lab to accurately calculate all of the cost of ownership factors related to EUV lithography. By having a clear understanding of EUV lithography's underlying economics, Lab scientists are better able to design more cost-effective solutions.

The Lab will also enjoy spin-on benefits from EUV lithography as the technology is further improved. The further development of EUV lithography will result in improvements over time in grating and instrumentation technologies that will allow ICF target $\mathrm{X}$-ray diagnostics to be improved. Thus, the spin-off from ICF technology will in the long run improve the Lab's infrastructure and therefore, its ability to perform its principal missions.

\section{Micropower Impulse Radar}

Micropower Impulse Radar (MIR) Technology. Micropower impulse radar (MIR) is sensing device that bounces very short, or microwave impulses off of objects and then returns a signal back to an antenna. Conventional radar works by emitting pulses of radio waves that bounce off objects and then send a return signal back to an antenna. The radar calculates the distance to an object by measuring the time it takes for the reflected signal to return. Historically, radar devices have been too expensive and too large to be incorporated into every day consumer products. Furthermore, radar does not work well over short distances because outgoing pulses can interfere with incoming echoes. By using $\$ 10$ worth of off-the-shelf electronic components, micropower impulse radar technology (MIR) surmounts conventional radar's deficiencies at near power distances because it sends out extremely short, rapid pulses, and then "samples," or listens for echoes that return from a specific distance. This means that the antenna on an MIR device creates a sensory spatial "bubble" and detects only those objects that penetrate the perimeter. It is even possible to set up an array of MIR sensors to form several bubbles that can determine whether an object is moving in a particular direction. Because of its relatively high operating frequency, and broad bandwidth (spread of frequencies), an MIR device has the ability to operate through barriers such as doors, walls, and floors, and other non-metallic objects.

Although sensor technologies that are presently available provide viable solutions for sensing and detection, they are hardly foolproof. For example, the common infrared sensor is popular because it is readily available, can run for a long period on the same batteries, and is difficult to subvert. However, infrared cannot penetrate objects, it relies on an expensive sensing element, and heat or sunlight can trigger a false alarm. Likewise, microwave motion sensors can be easily triggered, they emit measurable electromagnetic radiation, and are made of expensive components. On the 
other hand, prototype MIR devices can run for a year on a pair of AA batteries, and only emit a millionth as much radiation as a cellular phone. MIR's components fit on a 1.5-inch square circuit board that costs about $\$ 10$, although within a few years the technology is expected to be collapsed onto a single silicon chip selling for $\$ 1$ to $\$ 2$ each.

An important caveat should be stated regarding the timing of MIR's adaptation to consumer products and other applications. While LLNL has developed the underlying technology that makes MIR work, it will be necessary for private sector firms to invest in further R\&D in order to adapt MIR to any given product. These customization costs can be expensive both in dollars and in time. While the firms that have purchased licenses for MIR from LLNL expect to develop a new product based on MIR, success is not guaranteed. Furthermore, MIR is one of several radio frequency technologies that could be adapted for sensing and detecting. It is therefore difficult to predict when MIR will have an impact on a particular product category, or within a given market.

MIR's Link to LLNL's Laser Program. Like EUV lithography, MIR was developed as part of the diagnostics program related to the NOVA laser. However, unlike EUV, which in and of itself is not related to the laser program's core mission, MIR was explicitly developed to assist in the diagnostic process.

The lab needed a faster and less expensive device for generating a sequence of photographs of the imploding fuel capsule taken during the laser experiments than had been previously employed. Researchers wanted to be able to take thirty such photographs in a billionth of a second, essentially making up a short motion picture of the implosion. In order to do this, Lab scientists had to design a "shutter" that could capture each image in 30 trillionths of a second. Thomas E. McEwan, an electrical engineer with expertise in high-speed microelectronics, came up with a solution that brought together his previous experience in counter-Stealth radar at Northrop Corp. with recent work at LLNL focusing on high power pulse generators. McEwan's breakthrough invention, the micropower impulse radar, works by emitting a series of extremely short (30 trillionths of a second) low power pulses with very broad bandwidth.

The MIR won an $R \& D 100$ Award in both 1993 and 1996 because of its unique ability to record many samples from a single electrical event. In fact, not only does McEwan's invention outperform -high speed oscilloscopes selling for $\$ 40,000$, it is smaller, sturdier, uses less power, and costs a fraction to produce. In addition to the $R \& D 100 \mathrm{Award}$, McEwan has also received an award from Popular Science magazine in 1994 for designing one of the 100 greatest inventions in science and technology, and from the Federal Laboratory Consortium for excellence in transferring technology from a laboratory to a private business.

MIR Patents and Licenses. LLNL has obtained 15 patents on MIR and has 10 more in the application filing phase. MIR's commercial potential was recognized from its inception when Tom McEwan first thought "it would make a very cool burglar alarm." From the outset the Lab has worked to foster the commercial application of MIR and to communicate to private industry that this technology is available for licensing. A March 1994 press conference announcing the first licensing of MIR by Amerigon Corp. in Monrovia, Calif., was very successful in establishing 
awareness of MIR technology. This event was consciously leveraged by the director of LLNL's Public Affairs Office who has been diligent in keeping MIR in the news through press-releases, pro-active contacts with the technology press, and by arranging Lab tours for journalists and technology writers. Efforts by the Public Affairs Office have paid off in terms of awards, magazine cover stories (Popular Science and The New Scientist), and commercial interest. Since its announcement in 1994, MIR has attracted more than 4,000 inquiries from businesses interested in its commercial potential.

\section{Impacts on the Economy}

MIR is a fundamental, enabling technology. Once its engineering is perfected, it will be incorporated into a variety of devices in a wide array of product categories. The potential economic benefits of MIR are so great that several of the Lab's licensees expect to be able to sell the results of their development work to firms in other industries. In the words of Paul Saffo, director of the Institute for the Future in Menlo Park, Calif., MIR "is one of those foundational technologies where people can only begin to guess at the important applications it will have."

While MIR has the potential to bring low-cost radar technology to everyday consumer appliances, it is still in a relatively immature phase of development. Firms that license MIR from the Lab in order to develop a new product are required to make a considerable investment of time and money to bring that product to fruition.

While it is impossible to begin to predict all of the sectors that will be impacted by having access to an inexpensive sensing device, 15 companies have already entered into licensing agreements with LLNL to utilize this technology. Most licensee firms insist on confidentiality until their products are ready for market. However, BAE interviewed three MIR licensees in three different sectors: the auto safety, fluid level sensing, and electronic tools industries to get feedback on how MIR could impact these industries. Several other areas where MIR could have a profound effect, including medical instruments, and which are significant industries in themselves, are profiled in the Quality of Life section below, since this, rather than economic growth, is likely to be the biggest impact of these applications.

Automobile Safety. Several car models currently have ultrasonic technology based sensors for safety and collision avoidance, but they are adversely affected by temperature, weather, and other environmental conditions. For example, infrared sensors have an unreliable detection range, and they can be triggered by light or heat. MIR-based sensors have the potential to be more reliable, robust, and less expensive than existing automotive radar technology. In the future, MIR could provide an integrated safety system for parking assistance, backup warning, collision avoidance, and airbag deployment. Tests have shown that unlike existing radar apparatus, MIR radar can function despite being covered with layers of mud or ice.

MIR licensees expect MIR devices to be used to warn drivers of vehicles in a blind spot, or during a collision to provide safer deployment of air bags. Sensors could also be used to detect potholes and bumps and could adjust the car's suspension accordingly. MIR sensors could also function as 
electronic dipsticks for all automotive fluids. "You might have as many as ten different applications of radar on your car," says Tom McEwan. This technology could also be developed into to safety systems for boats, bicycles, and other vehicles.

Amerigon, Inc. of Monrovia, Calif. was the first company to license MIR technology. Although future licenses have all been non-exclusive, Amerigon was able to obtain sole rights to one type of MIR technology for applications in automotive safety. Amerigon's potential products include a backup warning system, blind spot sensors, and an improved air bag deployment system. Amerigon has already sold prototypes of its backup warning systems to auto manufacturers, and this technology may appear in vehicles by the end of the century at a cost of only $\$ 200$ per car. Founded in 1991, and with 90 employees and $\$ 7.8$ million in annual sales, Amerigon is partnering with AlliedSignal Inc., of Morristown, N.J., one of the auto industry's largest suppliers of airbags, to jointly develop a complete auto safety system. In addition to MIR safety devices, Amerigon is also working on an MIR-based voice-activated audio navigation system, and electrically heated and cooled seats for the luxury car market. However, because of the auto industry's three year design cycle, MIR-based auto components are not expected to be available before the model year 2000 .

If four or five MIR-based sensors, with a total value of $\$ 200$, are included in each of the 14 million new cars and trucks sold every year in the U.S., the potential U.S. market for auto- related MIR products could be as much as $\$ 2.8$ billion per year. This number could greatly expand if MIR devices could be easily installed into the existing 180 million cars and trucks in use in the U.S.

Fluid Level Sensing. U.S. industries ranging from beverage manufacturing and food processing to petrochemicals spend $\$ 1$ billion annually on sensing devices that provide accurate measurements of fluids and solids in vats, silos, and tanks. Current fluid level sensing technology often must function in the adverse conditions inherent to flammable liquids or corrosive or explosive materials. For some applications, existing technology gives measurement readings that, depending on the environment, can be quite variable. A liquid that generates froth or bubbles can cause false readings in ultrasound sensors because sound waves cannot distinguish between liquid and foam. Other sensors can give faulty readings because of changes in temperature or humidity, or when exposed to water condensation.

MIR technology can overcome most of these problems because it is not influenced by environmental conditions. MIR will be able to deliver highly accurate fluid level sensing either as part of a simple non-moving strip mounted on an exterior wall, or as a transmission wire that serves as a dipstick ranging from several inches to dozens of feet. An MIR unit could give continuous readout of fluid levels, or could be combined with a switch mechanism to open or close a valve depending on whether a tank were empty or full. MIR will be able to offer all of these capabilities with greater accuracy and at a lower cost than existing sensing technologies.

Two MIR licensees who are currently exploring its use as a fluid level sensor include Pile Dynamics, Inc. of Cleveland, Ohio, and Remote Data Systems of Wilmington, North Carolina. Pile Dynamics has taken out a license from LLNL for the development of a system to assist 
construction crews in installing foundation piles. Their instrument will provide measurements of how deeply a steel or concrete pile has penetrated, and how much of it remains to be driven into the ground. Remote Data Systems is working on a monitor for rivers and streams to help detect rising water and flash floods. This device can also be used by waste water treatment facilities to ensure that retaining ponds do not overflow.

Titan Technologies, a Canadian firm headquartered in Edmonton, Alberta, manufactures level controls for petroleum, gas, and chemical manufacturing. In 1997 it will begin selling an electronic dipstick, one of the first commercial applications of MIR. Titan's product will initially be used for industrial fluid monitoring and will be lower in cost compared to both conventional mechanical float sensors and conventional radar sensors. With a small and light design, Titan's radar will also be one-tenth the size of existing equipment. Titan expects its dipstick to be reduced in size and in price when MIR circuitry is condensed onto a single microchip. John Grimes, Titan's vice-president of research and development, believes "the radar technology will dramatically change the fluid level sensing industry."

Electronic Tools. Electronic tools are one of the first applications consumers are likely to see incorporating MIR technology. Possible devices include: laser tape measures, wireless thermostats, automatic dispensers, and toys and games utilizing low-cost sensors.

The first electronic tool with an MIR sensor will be available from Zircon Corp., an LLNL licensee that is headquartered in Campbell, Calif. Zircon makes high tech electronic hand tools for both professionals and amateurs, including the popular StudSensorm, a non-radar sensor for detecting wall studs. Other Zircon products include a laser level, a water level sensor, and other electronic sensing devices. The company's first MIR-based tool will be a hand-held detector for locating steel rebar in concrete and steel pipes in walls.

Other MIR products on Zircon's horizon include a sensor to locate subterranean objects such as wires, metal or plastic pipes, and sewer lines. Future products may include electric hand tools that sound an alarm if the user gets too close to an object, or that switch off when hidden dangers are detected. John Stauss, president of Zircon feels that MIR-based products will soon be ubiquitous because they will "do quickly and cheaply what other technologies can only do inelegantly or expensively, or not at all."

\section{Impacts on Science and Technology}

Tom McEwan, MIR's inventor feels the radar is "really turning out to be a Swiss Army knife" because it is such a multi-purpose tool. Engineers at LLNL expect MIR technology to find its way into hundreds of products including space heaters that shut off if a child comes too close, elevator doors that don't shut on people, autofocus cameras with improved distance calculators, smart appliances, and smart climate control systems that turn lights and thermostats on and off when you enter or leave a room. Lab scientists are currently exploring virtual reality (VR) applications to determine if MIR can be used for 3-D spatial renderings, or can be incorporated into a VR headset 
that senses body position. LLNL is also working with the Department of Transportation to develop a tool to help engineers detect corrosion of steel reinforcements for bridge pilings.

\section{Impacts on Quality of Life}

As with EUV, many of MIR's potential applications have not yet been conceived. Nevertheless, it is hard to think of any product related to consumer electronics, safety equipment, medical devices, or transportation that will not benefit from inexpensive and reliable sensing technology. MIR's most immediate impact in terms of quality of life will most likely be its application to medical technology, rescue equipment, land mine detection, and security and surveillance. Although all four areas are profiled below, the latter two have the best near term potential.

Medical Instruments. Given that the radiation emissions of an MIR device are very sensitive to minute motions, but are a million times less powerful than a cellular phone, MIR has excellent potential as a medically safe, non-invasive, diagnostic tool. With the appropriate imaging equipment, MIR could be used for respiration, heart, and pre-natal monitoring. It could also provide a low-radiation alternative to X-rays and ultrasound, and offers the capability of seeing inside the body without invasive surgery. The U.S. Army is even investigating the design of radar patches to be sewn into a soldier's uniform in order to give medics instant vital signs.

A potentially widespread application for MIR technology may be as a radar stethoscope. As a non-acoustic device, an MIR scope could detect breathing movement in the chest that is not manifested using a conventional stethoscope. MIR would register the movement of the heart muscle rather than the sound of pumping blood, thus making it especially useful in a noisy emergency room or on a battlefield. According to Dr. Elaine Ashby, a practicing physician and LLNL's medical liaison, MIR "very likely will replace the stethoscope."

Another medical device with strong potential is the use of MIR in a heart monitor which measures the heart muscle's contractions rather than the electrical impulses captured in a conventional electrocardiogram (ECG). Lab engineers eventually expect MIR to work in combination with an ECG monitor because MIR is able to detect heart contractions that give a "flat line" display on an ECG.

MIR could also be used as a respiration monitor for hospital patients, as well as a SIDS (sudden infant death syndrome) monitor for infants because it can detect the motion of the lungs. It is not necessary for such a monitor to be in contact with a person's body, meaning that a sensor placed in a crib mattress could sound an immediate alert if the infant stopped breathing.

Although ultrasound imaging has many benefits, it cannot penetrate bone and is not able to reach all organs. Furthermore, ultrasound images often lack contrast because the technology does not distinguish very well between different tissues. On the other hand, the short pulses from an MIR device produce data-rich return signals which can be used to generate higher resolution images. By using two radars with overlapping "bubbles" and connecting them to a computer, Lab engineers have been able construct images of objects detected by MIR. When this technology is 
perfected, engineers expect to develop a radar that can produce three-dimensional images of blood vessels, organs behind ribs, or the spinal column. MIR radar will allow physicians to be able to diagnose bone fractures without the use of X-rays, or locate bullet fragments in wounded patients. Tom McEwan believes that MIR "is going to completely phase out ultrasound." Other experts, including many outside LLNL, are also enthusiastic about MIR's medical applications. Mike Hopmeier from the Air Force's Wright Laboratory has said that MIR "opens up an entirely new world of medical diagnostics," while Dr. Elaine Ashby states, "I feel this is going to be one of the most revolutionary things to hit medical science."

It must be noted that it is not clear when MIR will be adapted for medical instruments, especially given the cost and lengthy time horizon for additional research and development, as well as FDA approval. Lab scientists estimate that medical applications for MIR will appear within 10 to 15 years.

Rescue Operations. MIR technology could also be used to create a device capable of detecting survivors buried under debris left after an earthquake, tornado, hurricane, explosion, avalanche, or other disaster. Currently, rescuers use dogs, cameras, and acoustic equipment to locate buried bodies, but a rubble-penetrating MIR device would provide greater efficiency because of its ability to detect heart and lung motions. Another benefit of MIR is that such a device could be attached to a frisbee-like disk and thrown into unstable wreckage to detect signs of life. LLNL is currently working with the U.S. Army Corps of Engineers Earthquake Preparedness Center to develop prototype rescue equipment.

Land Mine Detection. A significant humanitarian need, and one of the greatest near term applications for this technology, is the use of MIR in land mine sensing devices. According to the Wall Street Journal, the U.S. State Department has estimated that the 12 countries most affected (e.g., Iraq, Afghanistan, Angola, etc.) have between 38 and 53 million uncleared land mines. The Red Cross estimates that there are more than 100 million land mines deployed worldwide. This problem is compounded by the fact that another 1.5 million mines are added to the count each year. As many as 25,000 people, many of them children, are maimed or killed each year by mines. Every year United Nations workers clear approximately 100,000 land mines at a significant financial cost. Although the mine itself is often as cheap as five dollars, it can cost up to $\$ 1,000$ to locate and clear or defuse it.

Anti-mine equipment carried by U.S. soldiers today employs the same basic technology used by U.S. troops during World War II-a metal detecting device and a fiberglass rod. These instruments are clearly inadequate given the difficulty of detecting sophisticated plastic mines. Within the next year the Army expects to deploy a helicopter-mounted detection system to locate land mines in Bosnia. This is a positive step toward applying new technology to mine detection, but it does not address the problem at the level of the individual soldier. While members of the House National Security Committee have expressed skepticism regarding the adequacy of the land mine detection "tool box" supplied to U.S. soldiers, MIR technology could offer a state-of-the-art yet cost effective solution. LLNL has recently received $\$ 300,000$ in DOD research funding to develop a hand-held mine detection radar that can display images of subterranean objects. 
Security Systems and Border Surveillance. Residential, office, and industrial security systems currently cost thousands of dollars to install and maintain. Security systems that are based on infrared or microwave sensor technology are sometimes less than adequate because they can be hard to conceal, or can be easily triggered by sunlight, pets, or even insects. An MIR-based security system offers many advantages over current technology, the greatest of which is its ability to penetrate solid objects in the same way that cordless phone signals can move through walls. This means a sensor can function even if it is placed behind an object, making MIR virtually undetectable. MIR can even be programmed to detect motion two feet above the floor, thus eliminating an alarm triggered by a roaming pet. A residential intrusion alarm system could be combined with a transmitter to switch on a siren or to automatically dial the police. Prototype MIR-based security systems that have been installed at LLNL as well as a DOE nuclear weapons complex have proven the effectiveness of this technology.

Much of the $\$ 5.5$ billion market for home and office security systems represents the costs of expensive security equipment to end users. MIR security sensors are anticipated to cost as little as $\$ 20$ each and, because of their low power requirements, will be able to run for lengthy periods on pair of AA batteries. By bringing down the cost of security, MIR could serve as a catalyst for expanding the market into areas that are not served currently because of the expense. MIR radar could also be applied to perimeter surveillance, radar trip wires, automatic doors, and keyless building entry for office and industrial sites.

In addition to home and office security, MIR has the potential to deliver automated surveillance systems for police boundaries, military sites, and international borders. In some instances, visible surveillance equipment such as cameras or antennae can be a target for attack or vandalism. A concealable MIR unit, combined with low cost computation and communication equipment, could detect intrusion in a localized area, or could be part of an integrated system of electronic trip lines ranging from several feet to several miles. MIR surveillance devices are currently in place at the El Centro, Calif. Border Patrol station.

\section{Impacts on the Lab}

Although there are competing radar research efforts in the private sector, industry experts agree that MIR probably would not have been developed outside of LLNL. The exacting requirements for laser diagnostic equipment, the unique capabilities of Lab scientists, and the Lab's willingness to support speculative research efforts, all combined to give an impetus to MIR that would not have been available in any other environment.

Licensees pay the Lab $\$ 100,000$ for the non-exclusive right to develop MIR-based applications. This arrangement transfers most of the risk of further $R \& D$ to the private sector. At the same time, the Lab is able to function as a sounding board for MIR licensees and provide guidance to their in-house research. Typically, engineers engaged in private sector R\&D do not communicate with their counterparts at competing firms. While this helps to maintain proprietary knowledge, there is considerable potential for wasted or duplicated effort. However, in the case of MIR 
licensees, engineers from private industry have access to other experts in their field because they are able to contact Lab scientists to discuss technical issues.

\section{EUV Lithography and MIR Case Study Conclusions}

The development of both EUV lithography and MIR technology provides interesting insights into the specific ways in which technology derived from the LLNL's laser program can have a broad array of impacts. However, the impact assessments for EUV lithography and MIR alone do not tell the entire story in terms of lessons that can be learned from these two cases. By comparing the two, a more complex picture of the impacts and implications such technological innovations could have for the economy emerges. In making this comparison, it becomes apparent that while both technologies will have impacts in all four general areas described below, the specifics of these impacts will vary considerably.

\section{Economic Impacts}

Breadth Versus Depth. The MIR technology could have a very broad economic impact extending across many sectors of the economy. While only a few industries are currently employing this technology, everybody familiar with MIR agrees that as it matures, it could be employed in a diverse range of applications, some of which may not be imagined at this point in time. In contrast, EUV lithography is currently being developed for application in only one industry: semiconductors. However, assuming EUV lithography will contribute to resolving the technical roadblocks confronting this industry, and given the magnitude of the impact the semiconductor industry has on the electronics industry, this single contribution could ultimately have more significant economic implications than MIR.

Job Creation Versus Job Retention. Based on the very small sample of firms included in the case studies, it appears that MIR has the potential to foster significant new business formation, and thus new job creation. Because this technology is so innovative, yet so inexpensive, it is likely that once it has matured, small entrepreneurs will find new applications for it, making MIR a core enabling technology. One such business has already been formed, and two of the companies that have licensed MIR are engaged in research and development activities that their owners understand may transform these establishments into entirely different types of firms.

The EUV lithography development process tells almost the opposite story. This technology is being developed to help the U.S. semiconductor industry remain competitive in a very aggressive global market. The Japanese are also trying to achieve the same advances in miniaturization, and to the extent that the U.S. can win the race to solve this problem, American semiconductor firms feel they have a distinct competitive advantage. However, because the cost of the fabrication facilities keeps increasing as the size of the transistors falls, it is likely that only a limited number of new facilities will be created that employ EUV lithography technology. In reality the most significant employment impacts 
resulting from EUV. lithography's commercialization are likely to occur in companies using semiconductors that could not have been produced without this technology, yet do not directly utilize EUV lithography.

Timing. The timeframe for commercialization of both these technologies is quite extensive. While this is not surprising for EUV which is a very complex technology, it is also true for MIR, which has been described as a relatively simple technology. Some of this time lag is related to the extensive time required to mature the MIR technology so that it can be incorporated into commercial applications, and some of this lag is related to the specific industries where the technology could be applied, i.e., the auto industry which has a three year design cycle.

Regional Impacts. These two technologies could have significantly different implications for regional development. Industries that incorporate MIR technology could be located anywhere in the U.S. since they are not necessarily tied to an industry that already has a strong tendency to "cluster" in one area. However, EUV lithography may have its most significant direct employment impact in the San Francisco Bay Area, a region that already accounts for many of the semiconductor equipment manufacturing companies in the U.S. Any new employment, or even retained jobs, that might otherwise have been lost if this industry were to fail to maintain even its current market position, are likely to be located in the Bay Area.

\section{Science and Technology Impacts}

Science Versus Technology. Both EUV lithography and MIR were developed as part of scientific research efforts. Yet, EUV lithography is, by definition, more heavily dependent on basic scientific research, primarily in the area of physics in both its development and eventual commercialization. The knowledge and information gained in developing EUV lithography already feeds directly back into the research being conducted for other parts of LLNL's laser program, including preliminary work for the NIF. This is not true for MIR. Although MIR is considered a very immature technology, the development work necessary for commercialization does not require the same level of basic research as EUV lithography. Researchers directly involved with this process do not feel that they are making new discoveries through their research efforts that will inform other parts of the scientific or research community. In essence, the EUV lithography development process seems to be leading to more knowledge and information, as well as creation of an important new technology. In contrast, MIR, as it matures, becomes more like a very high tech widget that people can use in all kinds of applications without ever understanding the underlying science, or gaining further scientific insights.

Scientist Versus Inventor. Because EUV lithography has required the use of considerable scientific research for its development, it has been developed by a group of scientists working together as a team. This effort has also benefited from considerable interaction with representatives from the semiconductor industry. MIR has been 
developed almost exclusively by one individual who has been classified as an "inventor." While development work on MIR has required team efforts on the part of the companies working on developing commercial applications for MIR, everybody agrees that none of these people have the same level of scientific or technical expertise as the original inventor.

Multidisciplinary Teams. In discussions with both industry experts and Lab staff, it appears that neither EUV lithography nor MIR could have been developed any place other than the National Lab system. These labs represent a unique assemblage of interdisciplinary science-based research teams with physical facilities that do not exist either in a university or private industry setting. Although several big companies, such as Xerox, have very strong multidisciplinary research teams, the particular combination of skills, interests, and infrastructure is different from what can be found at the labs.

In addition, the way in which these research teams work at the labs is also different from the research process in other settings. The most significant difference appears to be in the area of setting deadlines. Private research and development efforts are primarily motivated by the ability to bring new products to market quickly. At the labs, however, research is mission-based and long range projects are prominent. By having more time to experiment and explore, lab personnel can sometimes explore research options that would not be possible in a different context. This has been particularly true for EUV lithography, where the industry experts agree that no private company would have undertaken the initial exploration of this technology because, in part, it would have taken too long to develop.

\section{Quality of Life Impacts}

In this one area, MIR and EUV lithography converge in terms of their impacts. Both will have significant potential to improve the quality of life for people in many different ways.

\section{Impacts on LLNL}

Advancements in Knowledge. As was described above, EUV lithography is already contributing back to the Lab in terms of the scientific knowledge that has been gained that will have relevance to the NIF and other laser related research. In addition, EUV lithography research has attracted over $\$ 75$ million in private investment over the past three years. Over the next three years this research program is likely to be funded entirely by private industry. As a result, the Lab will retain its capability to do this type of physics research, will have the benefit of the first hand knowledge that will come out of this research, and may continue to make breakthroughs that will be applicable to other aspects of the laser program.

Additional Revenue. The majority of the development work necessary for commercializing MIR is being done outside of the Lab. Therefore, most of the 
accumulated knowledge related to this research will also remain outside of the Lab. However, as MIR technology matures, more companies will be interested in licensing it from the Lab. At a cost of $\$ 100,000$ a piece, these licenses and the subsequent royalties could, over the long run generate significant revenues for the Lab which could be reinvested in other technology development activities. 


\section{NIF RELATED TECHNOLOGICAL INNOVATIONS}

While it is impossible to predict exactly what technical spin-offs will result from the construction and operation of NIF, it is possible to identify some technologies whose state-of-the-art will be advanced during this process. It is also possible, although somewhat speculative, to identify possible commercial applications of those technical improvements.

The technical advances will come from two sources: 1) those developments directly related to NIF which are necessary to meet performance, cost, and schedule goals, and 2) those developments occurring in the ICF program, either concurrent with or following NIF construction, related to obtaining data from NIF experiments.

The cost of a high power laser is almost directly proportional to the amount of energy in the laser light being sent to the target, unless there are improvements in component technology and manufacturing processes. This is because the cost of optical components is proportional to the surface area needing precision forming, polishing and finishing processes, and the surface area required is proportional to the light energy transmitted. The NIF laser will have forty times the energy of the Nova laser. However, its cost is estimated by the project team to be only 2.5 to 3 times that of Nova. This is possible because of improvements in both the components themselves and in the processes used to manufacture them. For example, increasing the damage threshold of optical components permits putting more light energy through a given surface area. Some of these improvements would be made within the broader context of the ICF program, with or without the NIF because the DOE National Laboratories have an ongoing charter from Congress to advance the state of the art of laser technology whether or not they are constructing a new large laser. However when a project like NIF is approved, the results of the past research are used in the design and the ongoing ICF research program becomes more focused on selected laser and optical component developments so that the rate of producing results is accelerated and directed toward certain size components. Thus it is appropriate to consider the innovations related to the ongoing ICF program as well as the NIF specific research in this assessment.

Research on solid state lasers, high speed instrumentation, pulsed power and other technical areas relevant to ICF is an ongoing activity at the four laboratories participating in design and construction of NIF. The NIF design takes advantage of past and anticipated near-term improvements in several areas. These present and anticipated improvements include higher damage threshold and broader bandwidth optical coatings, laser diode arrays for pumping lasers, higher energy-storage-density capacitors, higher power switches, large aperture diffractive optical components, lower-cost precision optical fabrication processes, and better instrumentation for measuring quality of parts. Each of these six areas is described in more detail below.

1. Optical Coatings. Increasing the damage threshold of optical coatings allows higher energy and power laser pulses to be transported with the same size of component. Increasing the bandwidth capability of the coatings allows greater flexibility in tuning lasers for an application. These two improvements can lead to commercial lasers with 
higher power per unit cost. This is important for commercial lasers used, for example, in manufacturing processes (e.g. laser cutting and welding) and in industrial laser measurements (e.g. distance measuring).

2. Laser Diode Arrays. Laser diodes efficiently convert electrical energy into light energy at a specific wavelength. In NIF laser diodes will be used to pump one of the preamplifier lasers in each beamline in order to increase its stability and efficiency. Higher efficiency translates into smaller power supplies and, therefore, lighter, cheaper, more energy-efficient industrial lasers. Laser diode arrays are under consideration for use in many space missions and in medical applications. In the future, inertial fusion power plants may be driven by diode-pumped solid state lasers because they promise to be efficient and operate with high pulse rates. The development and use of laser diode arrays in the near term for NIF will help lower the cost of these pumps and give experience producing large numbers at reasonable cost.

3. High Energy Storage Density for Capacitors. Pulsed power equipment is used to drive the flashlamps that make the NIF laser amplifiers work. To reduce the cost of the NIF pulsed power equipment, research is being directed toward increasing the energy storage density of large commercial capacitors and toward increasing the power that each switch can handle. Flashlamps are used commercially to treat food so that it will have a longer shelf life, i.e. take longer to spoil. Although the flashlamps used in the commercial process are different from NIF's, the pulsed power that drives them is similar. Therefore, lowering the cost of pulsed power equipment like that used for NIF will make the UV treatment of food more competitive. In addition the improvements in pulsed power equipment could have a beneficial cost saving effect in other places where large energy storage units or high power switches are needed, such as in large scientific facilities (like accelerators), rail guns developed for the military and in rock crushing operations.

4. Diffractive Optical Components. Diffractive optical components perform the same function as refractive optics (e.g. lenses, wedges) but are much thinner. To perform their functions diffractive optics have thin surface coatings that have a precision microstructure such as a series of lines, grooves, or circles. Progress in diffractive optics for high power lasers has depended upon the ability to construct such microstructures with the required precision on larger and larger surfaces. NIF anticipates using such diffractive optics at sizes up to the full aperture $(40 \times 40 \mathrm{~cm})$. Flat panel displays, such as those used on laptop computers, are made by a variety of techniques. One promising new technology for such displays are field emission plates. This type of flat panel display requires constructing, on a suitable substrate, a two dimensional array of tiny, precision peaks. The techniques for fabricating NIF diffractive optical components lend themselves to fabricating such arrays quickly and inexpensively. Thus, this NIF development could have benefit for future flat panel displays and any electronic systems that can use them (computers and television sets). 
5. Precision Optical Components. The number of precision optical components required by NIF justifies development of new manufacturing processes to lower the unit cost. Cooperative research with optical fabrication companies is focusing on applying mass production techniques to precision optical fabrication. For example, the laser glass slabs for Nova were manufactured using a batch processing mode. For the number of slabs needed for NIF, a continuous pour process is being developed. Similarly, forming, finishing, polishing and coating processes for glass components are being changed to make them less labor intensive and produce more units with fewer people and less (but improved) fabrication equipment Very large crystals of potassium dihydrogen phosphate (KDP) are also needed for NIF. Growing such large, pure crystals required more than two years for Nova but a new process recently developed would allow growing the required crystals in two to three months.

The developments in optical fabrication technology for NIF may have an important impact on commercial precision optics. In the past large aperture (beam diameter) optical components were so expensive that they were only practical for large government projects or for military systems. The new techniques being developed may allow such large optics to be competitive in some consumer products. For example, a representative of Hoya glass company stated that development of the continuous pour laser glass fabrication process may be adaptable to make UV filtering glass competitive enough to be used in automobile windshields. Such a development would reduce the average exposure to cancer producing UV solar radiation at a time when ozone depletion is increasing the risk globally.

6. Improve Test Instruments. To improve component performance or fabrication techniques also requires the availability of instruments capable of measuring the improved specification. For example, development of large aperture diffractive optical components required the development of a laser interferometer that could measure the precision microstructures created. This interferometer may help fabricators control the surface microstructure for other products, making the quality better and the cost less for large diameter optical components.

In addition to the NIF specific areas discussed above, the ongoing ICF program will make progress is other technical areas both during and after NIF construction. These other technical areas have more to do with the experiments to be done on NIF than with the technologies necessary to design and build it. The previous progress in technology areas that led to the EUV lithography and micropower impulse radar (MIR) capabilities discussed in Chapter $V$ are examples of this that have resulted from past ICF program activities. More such progress in these other areas is likely in the future. For example, improvements in temporal and spatial resolution of target performance instrumentation will continue. Further development of laser produced X-ray sources and in X-ray instrumentation can be expected because of improvements in the ability to diagnose target performance. This progress will occur symbiotically with the recently established application programs directed at EUV lithography and MIR technology. Progress in those former "spin-off" programs will "spin-on" to be used in the ICF program and developments in ICF will further "spin-off" to those programs. In addition, the NIF experimental program will require new 
technologies such as microfabrication of cryogenic ICF fusion targets. These symbiotic relationships and new technologies may in the future have applications to commercial products that it is, at present, impossible to foresee. 


\section{CONCLUSIONS}

Technological innovations linked to the ICF program at LLNL will have a significant impact on the U. S. economy. This trend should continue with the NIF which is already pushing the state of the art in several key technology areas. These innovations could have only been made at LLNL because of the unique research environment which includes extensive use of basic science, time frames for resolving research issues that are much longer than is typical in private industry, the large interdisciplinary teams of scientists, and the tremendous laboratory infrastructure. Although these innovations are not central to the Lab's core mission, the United States will only be able to maximize its return on its investment in the National Labs by allowing industry to benefit from these spin-off technologies. The impacts of these innovations extend beyond basic growth in the economy to include benefits for science and technology, overall quality of life, and positive residual benefits that flow back into the National Laboratory system. The following statements, organized by the major impact categories, summarize the significant findings of this report. Based on these conclusions, areas for further study are also presented.

\section{Economic Impacts}

1. Past discoveries from the ICF program at LLNL have the potential to impact industries which account for a significant portion of the current U.S. GDP.

The two technologies profiled in the case studies highlight this point. Extreme ultraviolet lithography and micropower impulse radar have the potential to impact huge industries such as electronics and automobiles. In the U.S. alone, the $\$ 424$ billion electronics market and the $\$ 176$ billion motor vehicle market represent almost 10 percent of gross domestic product. While neither the timing nor the magnitude of the impact by EUV or MIR on the electronics or motor vehicle sectors can be predicted, these statistics offer a reference point that demonstrates the potential significance of these two evolving technologies

\section{NIF and the expanded ICF program will push the state of the art in several technology areas that are likely to have significant impacts on the economy over the next 10 to 15 years.}

Given that early development activity related to NIF is already beginning to push the state of the art for laser and optics technologies, it appears likely that this facility will continue the past trend of the ICF program in that it will also produce innovative technologies. Based on experience with other technological innovation, both in general and with specific technologies emerging from the National Labs, it is very likely that these innovations will have impacts on the economy, science and research, quality of life, and on the future work of the labs. However, the specific nature of these impacts could vary considerably depending on the nature of the technology. 
3. While the total number of jobs created by the NIF's development, construction, and operation are relatively small compared to total employment in the San Francisco Bay Area, the quality of these jobs will be very high and will help the U.S. retain its competitiveness in several key sectors.

While the NIF's most significant impacts are likely to come from technological innovations, the jobs created by this facility's development, construction, and operation will also have important benefits. Although the absolute number of jobs being created $(6,165$ at the peak construction period, with 2,870 in the San Francisco Bay Area) is relatively small when compared with the total employment in the San Francisco Bay Area, it is nevertheless a significant number and the quality of these jobs is very high. For example the construction skills required to build the NIF are very different than those required to build a house. To the extent that the U.S. develops and maintains its capacity to produce advanced facilities, this country will continue to retain an existing competitive advantage in the design, engineering and construction industries. These skills are and will continue to be a factor in the decisions companies make as to where they locate new state of the art research facilities.

4. The NIF's full potential to generate economics benefits can only be realized if the National Labs continue to have strong interactive relationships with private industry.

In considering the overall impacts of the NIF, it is important to reiterate that this facility's primary missions are science-based stockpile stewardship and potential development of a new energy source. The benefits derived from these two activities alone should be sufficient to justify making the required $\$ 1.1$ billion investment. However, the U.S. can maximize its return on this investment if it continues to allow the labs to develop new technologies which emerge from their core research mission. This research and development activity, while it does not detract or redefine in any way the labs' primary mission, can have significant benefits for both the economy in general and the labs themselves.

\section{LLNL must maintain both vigilance and flexibility to ensure that future innovations reach} their full potential for dissemination in the economy.

LLNL has developed (aided by changes in federal law) a very strong culture that encourages its researchers to look for opportunities to apply their technological advances to specific industry applications. Without this cultural milieu, EUV lithography or MIR might never have been shared with anybody outside of the Lab. Had these technologies stayed within LLNL, it is likely that these would have been very significant "missed opportunities" for several very large industries world wide. 


\section{Science and Technology Impacts}

6. Basic scientific research applied to large, interdisciplinary projects, is the most powerful component driving technological innovation at LLNL.

Most private sector or university research institutions, both in the U.S. and abroad, do not have the capability to use basic science as the foundation for their work and apply it in real time to large, interdisciplinary projects. While not all research can or must be based on "big science," LLNL represents a very important source of this type of research competency which has enabled the U.S. to maintain a stronger and more diverse set of research skills than any other country in the world, including Japan.

7. Technological innovations emerging from the NIF are likely to be unique compared to innovations developed by other public or private research institutions in the U.S.

It is clear that the technologies emerging from the NIF are likely to be different from technological innovations emerging from any other research setting in the U.S. This is because LLNL has a unique combination of interdisciplinary research skills and physical infrastructure that expands, rather than duplicates or overlaps with the other research capabilities in this country. The experience with EUV lithography in particular shows that as the Lab develops technologies that are useful to industry, if the information is shared, the benefits to both parties are greater than what would have been gained without this sharing of information. Industry experts agree that EUV lithography would never have been developed without LLNL, and yet this technology has good potential for solving a major technical roadblock that will significantly influence the electronics industry, the largest industry in the world:

\section{Quality of Life Impacts}

8. Over the long run, the "quality of life" impacts from technological innovations associated with LLNL's ICF program may exceed the economic impacts.

At this time, it is very difficult to anticipate the full quality of life implications of both past and future technological innovations linked to the ICF program. Yet, the evidence just for the medical implications of MIR indicate that such impacts could cause major paradigm shifts in the entire field of medical diagnostics, which in turn could positively impact millions of peoples' lives. 


\section{Impacts on LLNL}

\section{The Lab's missions and infrastructure will benefit from innovations in its spin-off projects.}

In the process of applying certain technologies to commercial products, the Lab's core missions and its infrastructure will also benefit. For example some of the innovations made in conjunction with developing EUV lithography, a process that in itself is not necessarily critical to the Lab's core mission, are directly applicable to the advanced optics systems to be included in the NIF. Without the EUV lithography program, the Lab likely would have had to invest considerable time and financial resources into developing a similar process, without the spin-off benefits to industry.

\section{By developing a close working relationship with industry, the Lab strengthens its own research capabilities.}

Although the Lab and private industry are typically working to resolve very different technological issues, both groups have much to share with each other. A strong relationship between the two will help the Lab avoid reinventing the wheel in some areas, and will provide a better understanding of what other kinds of research capabilities exist in the U. S. Therefore, the Lab will not always have to develop all of its own technology, but may be able to take advantage of products and services already in existence, thus saving both time and money.

\section{Areas for Further Study}

While the research for this report has provided some insights into the general types of impacts that could result from developing the NIF, there are still many questions that remain unanswered. The following list outlines areas for further exploration that could help to provide more detailed information about the NIF's impacts.

1. Ways in which the commercialization process between the National Labs and industry can be modified to maximize efficiency.

2. Exploration of the general ways that new technologies can be integrated into regional economies to assist with economic development.

3. Further study of the specific relationship between the NIF and the Bay Area region given the area's high tech environment, and how both benefit from each other's presence.

4. Additional assessment of the ways in which the NIF's procurement process impacts industry and the economy.

5. Further research into developing methodologies to quantify the economic and social impacts of large technology based projects like the NIF. 
APPENDIX A: ADDITIONAL TECHNOLOGY PROFILES

60 


\section{Advanced Precision Optics}

"Advanced precision optics" is an umbrella term that encompasses applications ranging from commercial and military satellites to precision manufacturing equipment. Advanced optics are critical to LLNL's laser program because they are the basic components that allow lasers such as Nova and the NIF to function. Since the invention of the laser at Bell Laboratories in 1961, the U.S. has been a world leader in the optics industry, in part because it has been required to respond to the technical demands of defense- and energy-related laser programs run by the National Laboratories.

In the early years, before the laser was adopted by the private sector for commercial use, it was employed in classified federal programs such as inertial confinement fusion research, military satellites, and space exploration. Suppliers to these early federal projects transferred the expertise they gained in defense-related work to private sector applications. These efforts eventually led to the development of commercial satellites, medical lasers, and laser cutting, drilling, and welding equipment. At the same time, ongoing federal laser programs still required the industry to constantly fabricate components with ever-advancing capabilities.

LLNL has worked with the U.S. optics industry over three decades to develop state-of-the-art optical components required for the Lab's laser program. Since the 1974 development of the Janus laser, LLNL has been pushing the envelope of optical technology. The Janus laser was followed by the Argus and Shiva lasers. The Novette, a prototype laser built in 1983, was succeeded by the Nova laser which has been instrumental to understanding inertial confinement fusion. The Beamlet, built in 1994, is a prototype of the NIF and has demonstrated the feasibility of the NIF's underlying technology. When it is completed, the NIF will be the world's largest laser with 40 times the energy of the Nova laser.

While in previous years the Lab's laser program focused on obtaining optical components that achieved required performance advances, the NIF program seeks to simultaneously attain state-ofthe-art performance and significantly reduce manufacturing costs. This will be achieved by moving technology as quickly as possible into a production environment where the manufacturer has a strong incentive to reduce costs, while still meeting LLNL's specifications. For example, the volume of optics necessary for the NIF is unprecedented and will require the Lab's optics suppliers to alter their current production facilities. The complicated process for manufacturing 4,000 glass amplifier slabs for NIF will change from a batch melting process to continuous melting because the batch method is simply not an efficient way to meet such high demand. In order to make the transition from batch to continuous processing, manufacturers have worked closely with Lab scientists during a three-year development program to convert the production environment. Described by one Lab engineer as a "partnership of strengths," this process has eventually led to a new composition of glass that is easier and cheaper to melt, and has better performance. 
Another important advance at LLNL has been the development of rapid growth technology for KDP crystals which LLNL has developed jointly with Moscow State University. KDP (potassium dihydrogen phosphate) crystals are nonlinear optical crystals used for optical switches and frequency conversion in advanced laser systems. Traditionally, KDP crystals were grown from an aqueous solution at a very slow rate of roughly one millimeter per day. At that rate, it would take about two years to grow a KDP crystal that would meet the NIF's requirements. Furthermore, the traditional crystal growth process itself was challenging because the factors that resulted in an acceptable product were not well understood. It was also extremely risky in that there was no way to be certain at the end of two years that the crystal would even be useable-zero yield batches have been known to occur.

Realizing the magnitude of these obstacles, LLNL joined forces with scientists at Moscow State University who have expertise in the fundamentals of rapid crystal growth technology on a small scale. This partnership turned out to be an excellent marriage of skills because of LLNL's aptitude with engineering scale-up. Eventually the team developed a process which allows NIF-sized KDP crystals to grow at a rate of over 10 millimeters per day, meaning that crystals required for the NIF can be grown in months rather than years. In addition to its speed, the new process will cost less and is expected to result in very high yields.

LLNL and its industry partners have received a great deal of international recognition and numerous awards for their jointly-developed technical advances. Much of this technology has applications beyond the laser program, including:

1. Diamond turning: A method for using a precision lathe to directly machine a specular optical surface that requires no further polishing. This process is used for making optical components in satellite construction, for example.

2. Lapping technology: An efficient method for shaping and polishing precision plano optics used, for example, in building flat panel displays or optical or magnetic disk drives for computers.

3. Lens fabrication: A method for modifying the shape of an optical component that is being applied to the development of lenses for the next generation of ultraviolet lithography equipment.

4. Laser glass melting and forming: This technology is used for making amplifier glass used in lasers. It can also be used to fabricate special composition glass that transmits ultraviolet and infrared light and is used in medical and industrial instruments.

Expertise developed in the private sector to meet the rigorous technical requirements of LLNL's laser program has also been used for other scientific projects that demand state-of-the-art optics. For example, Tinsley Laboratories, Inc., a supplier of lenses for the Nova and Beamlet lasers, was 
able to supply customized precision optical components used to repair the Hubble Space Telescope in 1992. In the view of LLNL's private sector partners, the benefits of Lab-industry joint research efforts are of a long term nature. Hoya Corp., a supplier of laser disks to Nova expects optical technology breakthroughs generated by the Lab to last through the year 2020 .

The U.S. optics industry has estimated annual sales of $\$ 8.2$ billion. While the U.S. has been the leader in optics technology since the invention of the laser, global competition is a serious concern to firms in this industry because other countries are working hard to close the gap.

\section{Advanced Health Care Technologies}

While conducting laser research for the DOE at LLNL, Laser Program engineers realized that their expertise in lasers, sensors, and fiber optics could be applied to the development of sophisticated medical equipment. Within a short period of time, Lab scientists were able to demonstrate that laser technology could improve the quality of healthcare by simultaneously reducing the cost of medical procedures, and reducing physical stress to medical patients. The Lab has even established a Medical Photonics Laboratory to focus on applying laser technology to medicine. The Medical Photonics Laboratory currently has 12 research projects in development. Two laserbased technologies with very strong potential include tissue welding devices, and X-ray catheter to treat patients following balloon angioplasty procedures.

Laser research at LLNL has resulted in the discovery of smaller, more efficient sources of light than have historically been available. Some of the properties of these new lasers have led to entirely new ways of interacting with materials, including human tissue. For example, tissue welding permits physicians to heat cells until the structure of the proteins within them is altered, allowing the protein molecules of adjacent cells to stick to one another. While this technique is still in the exploratory stages, it is expected to permit a non-invasive method for sealing wounds. Lab scientists, in partnership with private sector firms, are working to understand the exact mechanism for tissue bonding, and to develop a highly accurate hand-held instrument that can distinguish between healthy and diseased tissue. Scientists are also trying to formulate a protein mixture that can function as tissue solder. Early results have been achieved using an albumen compound that has been mixed with a dye that absorbs light at a specific frequency. A laser can then be used to heat the dyed solder solution, while avoiding the surrounding tissue.

$\mathrm{X}$-ray catheters, which will be used to treat angioplasty patients, generates a local dose of X-rays sufficient to stem uncontrolled growth of muscle cells in arteries. This uncontrolled growth usually leads to restenosis or reclosure of coronary arteries that have been opened with balloon angioplasty. This new disposable catheter technology provides all of the benefits now available with catheters which use radioactive sources but avoids the handling difficulties since the X-rays are produced only on demand.

The Medical Photonics Lab is also working on a laser recanalization system, i.e., a laser to produce minute shocks that break up clots without damaging arterial walls or sensitive cerebral 
tissue. If successful, this technology will be a useful treatment for victims of acute ischemic stroke or clots in cerebral arteries.

Each of theses devices must go through clinical trials and obtain FDA approval before they will be available to the medical community. Therefore, long before a technology is ready for commercialization, the Lab must obtain private sector interest and support. When they are confident that one of the Lab's advanced health care technologies is feasible, Lab scientists bring in end-users (doctors), large and small medical device firms, and potential investors in order to facilitate the commercialization process. To date, 10 firms are working with Lab scientists on projects to develop laser-based medical technology.

While no one can predict future sales or market share for laser-based medical devices that result from LLNL research efforts, it is still important to be aware of the significance of the market that these devices will join when they are commercialized. The U.S. market for electromedical equipment is estimated at $\$ 6$ billion annually.

\section{Field Emission Displays}

Flat panel displays (FPD) have a wide range of applications such as viewing screens in lap-top computers, head-mounted displays and large screen televisions. The worldwide flat panel display market has been forecasted to exceed $\$ 14$ billion annually by the turn of the century. Current FPD's in use are based on the active matrix liquid crystal display (AMLCD) technology. In this technology, optical properties of individual liquid crystal cells are altered by selective application of voltage. These cells act as light valves to transmit or block light from a backlit source. Such displays have limitations in terms of brightness, viewing angle and environmental ruggedness. Next-generation FPDs are expected to be based on a new concept called field emission. In a field emission display (FED), a stream of electrons ejected from the tip of a cathode is accelerated across a small vacuum gap and impinges on a phosphor screen to generate light. A FED screen consists of millions of tips and related circuitry fabricated on a monolithic substrate. In essence, each emitter tip is a tiny cathode ray tube, and there are thousands of emitter tips per pixel (the defining color unit) of the display. These emissive arrays are much brighter, have a much wider viewing angle, and can operate at much higher extremes of temperature than can liquid crystalbased displays.

Although the FED concept has been well known for many years, use of FED for display is still under development. One key parameter is the so called "turn on voltage"-the minimum voltage needed to light up the display. Current state of the art FEDs have a turn on voltage on the order of 100 volts or more. It is understood that to make FEDs attractive the turn on voltage has to be brought down to around five to 12 volts. The physics of FEDs dictate that the turn on voltage can be reduced by producing cathodes with finer and finer tips, typically about 0.1 micrometers (a millionth of a meter). 
To produce a reasonably sized working FED (e.g., the size of a 17-inch TV screen), one has to fabricate roughly half a billion cathode tips of 0.1 micron tip size placed regularly on a one micron period grid. The conventional lithographic process used in AMLCD manufacture does not have the resolution needed to write these fine features and suffers from stitching errors (edge irregularities resulting from joining two separately written fields) that are very visible to the eye. Electron beam writing lithography can meet resolution requirements but is prohibitively slow and expensive for large area displays. On the other hand, interference lithography using lasers (holography) is ideally suited for this purpose. In this process, a layer of photoresist is exposed to a cross grid interference pattern to produce a uniform array of submicron-period photoresist dots, each small enough to be used to pattern emitter tips 0.1 micrometer or smaller.

LLNL's Laser Program has been developing holographic technology for fabricating large aperture diffraction gratings for use on the Lab's petawatt laser (one petawatt equals one million gigawatts or one thousand terawatts; a terawatt is a trillion watts). This technology is directly applicable to making large area field emission FPDs, and, to date, LLNL has produced holographic gratings at sizes up to 94 centimeters. Production of FEDs by the holographic method represents a natural application of the holographic grating technology for FEDs and would help to maintain the competitive edge of the US display industry in the 21 st century. LLNL has demonstrated interference lithography for this application by creating uniform arrays of approximately 500 billion elements on $24 \times 24$ inch square substrates. LLNL scientists have also worked with FEDCorp, based in Hopewell Junction, New York, to create working field emitter arrays with a turn on voltage of approximately 17 volts. The importance of interference lithography to the U.S. flat panel display industry was recently underscored by the U.S. Display Consortium (a collection of private industries involved in FED development) when it selected the holographic method as the process of choice for fabrication of the FED of the future.

\section{High Density Magnetic Storage}

As computer performance improves, from faster microprocessor speeds to higher resolution displays, it is important for data retrieval rates from the computer's hard disk to keep pace. One of the factors that is critical to raising data retrieval rates is increased disk density. A computer's rigid disk drive works by magnetically reading and writing data to several stacked platters that are made of metal or glass. Each platter has many tracks and sectors that are read by the disk drive's recording head. High density magnetic storage differs from current magnetic storage devices in that it offers greater areal density, i.e., more bits of data storage per square inch of disk track. In fact, the Lab expects its research to result in improvements in current storage densities by a factor of 100-i.e., high density storage devices will permit 100 times the data to fit within the same area.

Because optic and magnetic storage media are often viewed as competing technologies, it may seem curious that LLNL's advancements in magnetic storage originated with work related to Xray optics techniques. However, Laser Program scientists who were familiar with both technologies quickly realized that their work in X-ray optics could have applications for the magnetic storage industry. At the same time, the elimination of nuclear testing and the adoption of 


\section{This sheet replaces page 66}

new policies for science-based stockpile stewardship have made it imperative to develop high density magnetic storage devices for future supercomputers. The advanced teraflop (a trillion instructions per second) computing technology that is needed to simulate nuclear blasts relies on prompt access to databases. This cannot be achieved without the vast improvements in magnetic storage technology that are offered by LLNL's work in high density magnetic media.

LLNL is currently in the middle of a four-year CRADA with Read-Rite Corporation of Milpitas, Calif., the largest independent supplier of disk recording heads. Lab and Read-Rite engineers are working to improve existing thin film recording head technology by a factor of 20 . Thin film heads are superior to traditional disk recording devices because they allow greater disk storage capacity, higher data retrieval rates, and higher data transfer rates. Current thin film technology has storage densities of 800 to 1,000 megabits per square inch ( 800 million to 1 billion bits per square inch). Read-Rite and the Lab are developing thin film heads with storage densities of two to 30 gigabits per square inch ( 30 billion bits per square inch).

\section{Micro Opties}

"Micro optics" refers to the production of ultrathin lenses that are used for medical, commercial, and military applications where space and weight limitations are critical. This technology permits the fabrication of lens membranes that are up to 1000 times thinner than lenses that are currently available. LLNL scientists became interested in micro optic technology several years ago because of its application to various diagnostic solutions that were being developed for the Lab's Inertial Confinement Fusion Program. Coincidentally, during this period an ophthalmologist from UCSF visited the Lab and inquired about the possibility of developing a color-corrected lens that would be thin enough for use in the human eye. Within a short time, Lab scientists were able to produce a color-corrected lens that was only a few microns thick, and thus the term "micro-thin" was used to describe these new lenses. Following this breakthrough the Lab was able to obtain funding from the DOE and private sector firms to continue working on micro optic technology. Its linkages to the Laser Program continue as micro optics remain one of the supporting technologies for the NIF.

Compared to the advantages offered by micro-thin lenses, current optical technology is bulky, and is limited by size and weight restrictions. Micro-thin optics are ultrathin, ultralight-weight, and flexible. They can be used for high resolution, light-weight applications where traditional optics are too large and inefficient. For example, replacing the eye's natural lens with a micro-thin lens in cataract surgery is expected to reduce the cost of the operation and improve the recovery period. A micro-thin lens could also be placed over the cornea to improve myopia, astigmatism, or other vision disorders.

While no one can predict future sales or market share for micro-thin lens technology, it is nevertheless important to be aware of the significance of the market that the micro-thin lens will join when it moves into commercial production. The U.S. market for ophthalmic goods, including contact lenses and intraocular lenses is estimated at $\$ 2.3$ billion annually. Micro-thin lens 
technology is also expected to have other applications including sensors, optical memories, scanners, and head mounted displays for military or virtual reality equipment.

\section{Laser Material Processing}

Laser materials processing typically involves drilling, cutting or patterning of material. Conventional laser cutting involves long (microsecond) pulses of a $\mathrm{CO}_{2}$ laser. The cutting is achieved by "boiling" off the material. This process is imprecise since it relies on the heat conducting properties of the material and is not easily applicable to insulating materials such as dielectrics. In addition, the conventional process results in considerable heating and thermal damage to nearby material which is not removed. Recent developments in high-power, shortpulse lasers have opened up a new avenue for laser material processing. It has been shown recently that the process of removal of the material when irradiated by very powerful short pulses is fundamentally different from long pulse processing. For short pulses, i.e., pulse durations of about one picosecond (one trillionth of a second) or less, material is removed by ablation without significant deposition of heat. This ablation, accompanied by the formation of a hot ionized vapor (plasma), is a nonlinear process with a sharp threshold in laser power. These features enable precision processing of materials using short, intense laser pulses since the material can be removed from a localized small region with each pulse.

The laser program at LLNL has been one of the pioneers in the development of high average power short pulse laser sources. LLNL's petawatt laser is the world's most powerful laser to date and represents the latest of such developments. Since only a small amount of material is removed during each laser pulse, laser material processing can be done using table-top terawatt class lasers delivering energies of the order of a few millijoules in pulses of the order of a picosecond long. LLNL has recently demonstrated extremely precise cutting of different type of materials using this process. Possible commercial applications of this technique are under exploration. 


$$
-
$$




\section{EUV Lithography Panel Discussion Questions}

We would like the panel to begin by discussing the importance of EUV lithography technology, highlighting the tangible benefits of achieving smaller chip geometries for applications such as advanced medical devices, or telecommunications applications. We would also like to know about EUV's potential impact on the economics of the semiconductor industry, and on the industry's ability to compete internationally in both the chip and equipment markets. We also need to play devil's advocate and ask about alternative lithography processes, as well as other technological hurdles inherent to silicon technology. Finally, we would like to know if you feel that the current system of working with LLNL could serve as a model for public-private collaboration for the development of new technologies.

1. What sort of new products will result from achieving chip geometries as small as 0.1microns?

Please give some examples of applications that will result from 0.1 -micron technology. What will we be able to have in the future, that we don't have today, because of this new level of miniaturization? Are the anticipated uses very specialized? Are they limited to defense and aerospace applications? Are there implications for products such as medical devices? What could smaller chips mean for advanced/affordable telecommunications systems? Are there any other compelling applications?

2. What will this technological leap mean to the economics of the semiconductor industry (i.e., will EUV contribute to perpetuating Moore's Law and for how long)?

We are aware that Moore's Law, the engine driving the semiconductor business, depends on lithography's ability to continually decrease the size of chip features, and that because of everadvancing lithography techniques, the industry has enjoyed 30 years of increasing output, lower costs per chip, and greater efficiency. Furthermore, we realize that these constant productivity gains have generated the profit margins that have allowed the industry to invest in new technology, which in turn has resulted in greater productivity.

Therefore, given that cost estimates for the next generation of fabs run as high as $\$ 3$ billion per plant, do you agree with analysts who predict that semiconductor capital costs will rise faster than revenues so that producers will not be able to make up for increasing costs by improving yields and equipment utilization because there is little room left for manufacturing efficiency? Do you believe that perfecting the EUV lithography process will help the semiconductor industry around this potential roadblock? 
3. Is there any way to predict what technological breakthroughs in lithography could mean for the shape of the semiconductor industry (i.e., what will be the impact of technological innovation on fab location decisions, the labor force profile, types of industrial alliances, etc.)?

The Semiconductor industry is currently shaped by many forces, including the globalization of the economy, which has caused companies to make different types of location decisions than they were making a decade ago. In a qualitative sense, can you tell us how technological innovation will further change the physical location of the semiconductor industry, the labor force needs of the industry, and the types of firms or industry alliances that might develop over time?

4. What are the pros and cons of alternative microlithography technologies such as X-ray synchrotron, electron beam, or ion beam lithography?

Can you comment on other potential replacements for optical lithography such as synchrotronbased X-ray, ion beam, and electron beam technologies? What is their potential for commercialization versus that of EUV? Does EUV have a cost advantage over the other alternatives?

5. How close is the industry to running up against the limits of silicon, and thus how much of a productivity gain will really be achieved from a break through in lithography?

In understanding the benefits of EUV, it seems important to understand whether or not EUV will allow the semiconductor industry to continue to achieve Moore's Law-driven productivity gains indefinitely, or whether EUV is just a band-aid before the industry is forced to develop alternatives to silicon-based chips.

Will EUV lithography, or the technology that provides an alternative to optical lithography, allow the semiconductor industry to continue to experience the productivity gains it has historically achieved for some extended period of time, or are there other roadblocks looming, such as the physical limits of silicon-based wafers, that will also have to be addressed?

6. In what ways has working with LLNL been a productive process? Could this be the beginning of a new model for collaboration between public research institutions and private industry?

Finally, we would like your general assessment of industry/LLNL collaboration and your view of the interaction between LLNL scientists and industry technologists. We are most interested in learning about your experience of working with the Lab, and whether you feel it is a possible model for collaboration for private sector firms who wish to take advantage of the 
research capabilities of public institutions. Do you feel that LLNL has a unique or significant role to play? What can you say about the Lab's role in the pre-development phase of EUV? Do you feel that there is a need to foster new or stronger relationships between private industry and public research? 


\section{Questions for MIR Licensees}

1. How did your firm originally become aware of MIR and how did you get involved with LLNL?

2. What are the impacts to your industry with respect to:

- Economic Impacts

- Science and Technology Impacts

- Quality of life impacts

3. What sort of new products or improved products will result from applying MIR technology to your industry? Is this a paradigm shift? How will it affect the cost and quality of your products?

4. What are competing technologies? What are their pros and cons? Is MIR better? Why or why not?

5. What are the costs of additional engineering or customizing of MIR technology? Are there other barriers?

6. What has been LLNL's role in this process? Is this a model for collaboration between public research institutions and private industry? How does working with LLNL differ from your internal R\&D process?

7. Firm sales:

Number of employees:

How large is your industry in terms of market size? 
APPENDLX C: DOCUMENTS JUSTIFYING NIF MISSION 


\section{Documents Justifying NIF Mission}

1. Inertial Confinement Fusion (ICF) Review, JSR-96-300, JASON, McLean, VA, March 1996

2. Justification of Mission Need, U.S. Department of Energy, Washington, D.C., January 1993

3. Nuclear Weapon Effects Test Facilitization of the National Ignition Facility $(U)$, Lawrence Livermore National Laboratory, Livermore, CA, August 8, 1995

4. The Role of the National Ignition Facility in the Development of Inertial Fusion Energy, UCRL-ID-1 19383, Lawrence Livermore National Laboratory, Livermore, CA, April 1995

5. Science Based Stockpile Stewardship, JSR-94-345, JASON, McLean, VA, November 1994

6. Science on High-Energy Lasers: From Today to the NIF, UCRL-ID-1 19170, Lawrence Livermore National Laboratory, Livermore, CA, January 1995

7. Second Review of the Department of Energy's Inertial Confinement Fusion Program Final Report, National Academy of Sciences, Washington, D.C., September 1990

8. The Stockpile Stewardship and Management Program, U.S. Department of Energy, Washington, D.C., May 1995

9. Technology Basis and Site Comparison Evaluation of the National Ignition Facility, U.S. Department of Energy, Oakland Operations Office, September 1996

10. Workshop on the Applications of High-Power Lasers to Science-Based Stockpile Stewardship 
APPENDIX D: BIBLIOGRAPHY 


\section{Bibliography}

1. “Agency Arms Lab With Funds For Unit That Sees Land Mines." Contra Costa Times 8 May 1996: 5A.

2. "Artisans of the tiny." Economist 30 September 1995: 97-98.

3. "Electronic Components and Equipment and Superconductors." U.S. Industrial Outlook 1994, Washington D.C.: U.S. Department. of Commerce, Chapter 15.

4. "Microchips Supplement," Forbes ASAP 26 February 1996.

5. "Micropower Impulse Radar." Futuretech (A Series of Briefings by Technical Insights, Inc.) July 1994: 1-12.

6. “Micropower Impulse Radar.” Science \& Technology Review January/February 1996: 16-29.

7. "The National Ignition Facility: An Overview." Energy \& Technology Review December 1994: 1-60.

8. "Radar Technology Licensed For Automotive Safety Applications." EDN 8 December 1994: 82.

9. Ajluni, Cheryl. "Low-Cost Wideband Spread-Spectrum Device Promises to Revolutionize Radar Proximity Sensors." Electronic Design 25 July 1994: 35-38.

10. Amerigon, Inc. 1995 Annual Report. Monrovia, California.

11. Armstrong, Larry. "Not Just a Blip on the Screen." Business Week 19 February 1996: 65.

12. Ashley, Steven. "Measuring Fluid Levels With Radar." Mechanical Engineering January 1996: 82-83.

13. Azevedo, S.G., D.T. Gavel, J.E. Mast and J.P. Warhus. Statement of Capabilities: Micropower Impulse Radar (MIR) Technology Applied to Mine Detection and Imaging. Document UCRL-ID-5366. Livermore, California: Lawrence Livermore National Laboratory, March 1995.

14. Ben-Itzak, Paul. "Intel, Energy Department Join Forces To Work On Faster Chips." San Francisco Examiner 16 October 1992: B3.

15. Bohn, Ronald A. and Mary A. Olsson. "Semiconductors: An Industry in Transition." The Red Herring September 1995: 46-55. 
16. Bremner, Brian. “Keiretsu Connections.” Business Week 22 July 1996: 52-54.

17. Clark, Don. "Livermore to Work On Chip Technology." San Francisco Chronicle 16 October 1992: B2.

18. Dacey, George C. "The U.S. Needs a National Technology Policy." Research-Technology Management January/February 1995: 9-11.

19. Dataquest Interactive. Lithography Stepper Capacity: Bottleneck of Semiconductor Production. (http://www.dataquest.com/register/abstracts/semm-ww/semm-ww-ma-9504-ab0001.html).

20. Dataquest Interactive. Research Highlights: Semiconductor Growth May Hinge on Backlog in Lithography Steppers. (http://www.dataquest.com/register/stories/semm-ww/semm-wwma-9504-pv-0001.html).

21. Dataquest Interactive. Research Highlights: Top Three Korean Semiconductor Manufacturers Take Part in Spending Boom in 1995.

(http://www.dataquest.com/register/stories/spsg-ww/spsg-ww-fr-9601-pv-0001.html).

22. Davis, James I. and Ralph R. Jacobs. "LLNL Proposes National Programs To Spur US Competitiveness." Laser Focus World April 1994: Reprint.

23. Derrington, Andrew. "How radar came home." Financial Times 14 October 1995: Reprint.

24. Dunn, Peter. "GCA, ASM Steppers to Debut at SPIE." Chilton's Electronic News 4 March 1991: 19.

25. Erkanat, Judy. "SPIE: Lithography at a Crossroads." Electronic News 18 March 1996: 2.

26. Fialka, John. "Killing Fields: Land Mines Prove to Be Even harder to Detect Than They Are to Ban." The Wall Street Journal 17 May 1996: A1.

27. Flanagan, Ruth. "The Pocket Radar." New Scientist 12 August 1995: 22-26.

28. Franson, Paul. "Tiny Radar Chip's Big Potential." London Financial Times 2 June 1995: Reprint.

29. Glaskin, Max. "They Could Monitor A Baby's Breathing, Detect Burglars, Find Landmines, Or Help Park The Car." Sunday Times (London) 31 March 1996.

30. Henderson, Rebecca. "Of Life Cycles Real and Imaginary: The Unexpectedly Long Old Age of Optical Lithography." Research Policy July 1995: 631-643. 
31. Hilstrom, Kevin, ed. Encyclopedia of American Industries. Detroit: Gale Research Inc., 1994.

32. Hogan, Hank. "Radio Wave Vision." The World \& $I$ (Washington Times Magazine) August 1995: 146-153.

33. Hutcheson, G. Dan and Jerry D. Hutcheson. "Technology and Economics in the Semiconductor Industry." Scientific American January 1996: 54-62.

34. Johnson, Roy R. "Laser Fusion Efforts in the United States." Optics \& Photonics News March 1995: 16-23.

35. Johnstone, Bob. "Research \& Innovation: Tricks with Light." Far Eastern Review 27 August 1992: 70 .

36. Johri, Pravin K. "Practical Issues in Scheduling and Dispatching in Semiconductor Wafer Fabrication." Journal of Manufacturing Systems 6 (1993): 474-485.

37. Kahn, Jeffery. "Science and Technology in a Competitive World." (http://www.lbl.gov/Science-Articles/Archive/sematech.html)

38. Kramer, David. "California Labs to Help U.S. Computing Industry Stay Competitive." Inside Energy 20 October 1992: Reprint.

39. Krisley, Joseph. "The growing importance of lighting controls." EC\&M 1 April 1995: 7.

40. Lawrence Livermore National Laboratory. Laser Program Highlights 1994. Oak Ridge, Tennessee: Office of Science and Technical Information, 1995.

41. Louis, Arthur. “A Really Booming Business.” San Francisco Chronicle 8 June 1996: D1.

42. Millson, Murray R., S. P. Raj, and David Wilemon. "Strategic Partnering for Developing New Products." Research-Technology Management. May/June 1996: 41-49

43. Moore, Gordon E. "Lithography and the Future of Moore's Law." SPIE Proceedings on Electron Beam, X-Ray, EUV, and Ion Beam Lithographies for Manufacturing February 1995 Reprint.

44. Livermore: Lawrence Livermore National Laboratory. Opportunities for Partnership. Second edition. Livermore, California: Industrial Partnerships and Commericialization Office, 1995.

45. Pellerin, Cheryl. "Consortia: Free Enterprise Meets Cooperation and the Results Can be Good for Robotics." Industrial Robotics 1 (1995): 31-33. 
46. Perkins, Michael, ed. The Red Herring Guide to the Digital Universe. New York: Warner Books, 1996.

47. Pressman, Lori, Sonia K. Guterman and Irene Abrams. "Pre-Production Investment and Jobs Induced by MIT Exclusive Patent Licenses: A Preliminary Model to Measure the Economic Impact of University Licensing." (http//:nhse.cs.rice.edu/autm/journal/95/PP195.html).

48. Rosenbloom, Richard S. and William J. Spencer, eds. Engines of Innovation: U.S. Industrial Research at the End of an Era. Boston, Massachusetts: Harvard Business School Press, 1996.

49. Secretary of Energy Advisory Board. "Alternative Futures for the Department of Energy National Laboratories” [Galvin Report]. (http://apollo.osti.gov.doe/whatsnew/galvin/v1.html)

50. Sematech. 1995 Annual Report. Austin, Texas: 1996.

51. Sematech. The National Technology Roadmap for Semiconductors. (http://www.sematech.org).

52. Semiconductor Industry Association (SIA). Research \& Technology: Ensuring Manufacturing Excellence Through Cooperation. (http://www.semichips.org/rd/coop.htm).

53. Semiconductor Industry Association (SIA). Research \& Technology: Ensuring U.S. Based Lithography Capability. (http://www.semichips.org/rd/litho.htm).

54. Shulman, Seth. “The National Labs Unplugged?" Technology Review October 1995: 15-17.

55. Silicon Valley Group. 1995 Annual Report. San Jose, California: 1996.

56. Slaby, C. Paul. "Where's the Fab?" Canadian Electronics March 1995: 1-6.

57. Smith, Hedrick. Rethinking America. New York: Avon Books, 1995.

58. Smith, Rebecca. "Electronics Firms, Livermore Lab Announce Deal to Make Chip Machine." San Jose Mercury News 16 October 1992: 6F.

59. Smith, Rebecca. "Radar for the Masses is on Horizon." San Jose Mercury News 24 April 1995: A1.

60. Standard \& Poor's. Standard \& Poor's Industry Surveys. New York: McGraw-Hill, 1996.

61. Stix, Gary. “Toward Point One." Scientific American February 1990: 90-95. 
62. Stover, Dawn. "Radar on a Chip: 101 Uses in Your Life." Popular Science March 1995: 107117.

63. Stowsky, Jay. "From Spin-Off to Spin-On: Redefining the Military's Role in Technology Development." The Berkeley Roundtable on the International Economy, Working Paper 50, May 1991.

64. Stowsky, Jay. "The Weakest Link: Semiconductor Production Equipment, Linkages, and the Limits to International Trade." The Berkeley Roundtable on the International Economy, Working Paper 27, August 1987.

65. Ultratech Stepper. 1995 Annual Report. San Jose, California: 1996.

66. Vargas, Dale. "Simple, Low-Cost Radar May Change Your Life." Sacramento Bee 6 March 1995: A1.

67. Vasilash, Gary S. "Micromachining: A Small Overview." Production September 1993: 5254. 


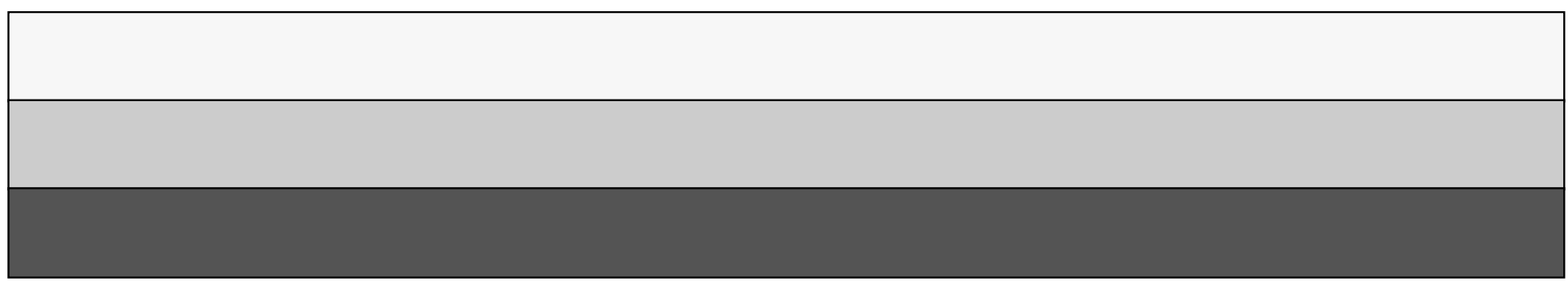

